\title{
MODERN MEDICINE AND THE 20TH CENTURY DECLINE IN MORTALITY: EVIDENCE ON THE IMPACT OF SULFA DRUGS
}

\author{
Seema Jayachandran \\ Adriana Lleras-Muney \\ Kimberly V. Smith \\ Working Paper 15089 \\ http://www.nber.org/papers/w15089
NATIONAL BUREAU OF ECONOMIC RESEARCH
1050 Massachusetts Avenue
Cambridge, MA 02138
June 2009

We are grateful to Melissa Thomasson for sharing her maternal mortality data and to James Trussell, Noreen Goldman, Ilyana Kuziemko, Ulrich Mueller, participants at the Office of Population Research seminar at Princeton University, two anonymous referees and the editors for helpful comments and suggestions. The views expressed herein are those of the author(s) and do not necessarily reflect the views of the National Bureau of Economic Research.

NBER working papers are circulated for discussion and comment purposes. They have not been peerreviewed or been subject to the review by the NBER Board of Directors that accompanies official NBER publications.

(C) 2009 by Seema Jayachandran, Adriana Lleras-Muney, and Kimberly V. Smith. All rights reserved. Short sections of text, not to exceed two paragraphs, may be quoted without explicit permission provided that full credit, including $(\odot)$ notice, is given to the source. 
Modern Medicine and the 20th Century Decline in Mortality: Evidence on the Impact of Sulfa Drugs

Seema Jayachandran, Adriana Lleras-Muney, and Kimberly V. Smith

NBER Working Paper No. 15089

June 2009

JEL No. I10,J11,N32

\section{ABSTRACT}

This paper studies the contribution of sulfa drugs, a groundbreaking medical innovation in the 1930s, to declines in U.S. mortality. For several often-fatal infectious diseases, sulfa drugs represented the first effective treatment. Using time-series and difference-in-differences methods (with diseases unaffected by sulfa drugs as a comparison group), we find that sulfa drugs led to a 25 to 40 percent decline in maternal mortality, 17 to 36 percent decline in pneumonia mortality, and 52 to 67 percent decline in scarlet-fever mortality between 1937 and 1943. Altogether, they reduced mortality by 2 to 4 percent and increased life expectancy by 0.4 to 0.8 years. We also find that sulfa drugs benefited whites more than blacks.

Seema Jayachandran

Department of Economics

Stanford University

579 Serra Mall

Stanford, CA 94305-6072

and NBER

jayachan@stanford.edu

Adriana Lleras-Muney

Department of Economics

9373 Bunche Hall

UCLA

Los Angeles, CA 90095

and NBER

alleras@ECON.UCLA.EDU
Kimberly V. Smith

Princeton, NJ

KSmith@mathematica-mpr.com 


\section{Introduction}

The U.S. experienced unprecedented declines in mortality during the $20^{\text {th }}$ century. The age-adjusted death rate decreased by 74 percent, and life expectancy increased by 56 percent, or 30 years (Bernard Guyer, Mary A. Freedman, Donna M. Strobino and Edward J. Sondik 2000). Seventy percent of the increase in longevity occurred during the first half of the century, driven by a reduction in infectious disease mortality, the leading cause of death at the time. The welfare gains from this increase in longevity are estimated to be as large as those from per capita GDP growth over the period (William D. Nordhaus 2002). Understanding what caused these rapid gains is of historical interest and also relevant for policy in developing countries today where infectious disease mortality remains high.

Several factors are thought to have contributed to the $20^{\text {th }}$-century declines in mortality, including rising living standards, better nutrition, and public health initiatives that improved water supplies, sanitation systems, and household hygiene (Thomas McKeown 1976, John B. McKinlay and Sonya M. McKinlay 1977, Robert W. Fogel 1994, Samuel Preston 1996, Preston and Michael Haines 1991, David Cutler and Grant Miller 2005).

The extent to which medical advances played a role in mortality decline during the first half of the $20^{\text {th }}$ century is subject to some debate. While studies focusing on the second half of the century attribute a large share of the decline to medical innovation (Cutler 2004), the importance of medicine for the earlier period is less well understood. Historical epidemiologists, such as McKeown, R.G. Record, and R.D. Turner (1975) and McKinlay and McKinlay (1977), observed that a large share of $20^{\text {th }}$-century declines in infectious disease mortality preceded the advent of medical treatments and concluded that the main cause of the advances must be something other than modern medicine. Other researchers hypothesized that medical innovation 
in fact was an important contributor to mortality declines, but they did not empirically test the hypothesis or estimate the magnitude of this contribution (e.g., Irvine Loudon 1987, John Conybeare 1948, Morton N. Swartz 2004).

The aim of this paper is to shed new light on the contribution of medical innovation to mortality declines by examining the introduction of sulfa drugs in the mid-1930s, an important event in the history of modern medicine. Sulfa drugs were the first medicine to effectively treat a range of potentially-fatal bacterial infections, including streptococcal (strep) infections (most notably scarlet fever, puerperal sepsis, and erysipelas), pneumonia, and meningitis. Pneumonia alone accounted for $8 \%$ of total deaths in 1936 . The production and sales of sulfa drugs grew rapidly after their discovery; by 1941, 10 to 15 million people were treated with sulfa drugs annually (Annabel Hecht 1984). The next major medical advance was not until the mid-1940s when penicillin and other antibiotics became available. Therefore, the period from the mid-1930s to mid-1940s provides a unique opportunity to examine the effect of a new medical technology on mortality.

Despite the historical and medical importance of sulfa drugs, there is little empirical evidence on their contribution to mortality decline. One exception is a study by Melissa A. Thomasson and Jaret Treber (2008) that finds that hospitalization of childbirth in the U.S. did not significantly reduce maternal mortality until after sulfa drugs became widely available in 1937. The limited empirical attention given to sulfa drugs may be due in part to the lack of disaggregated data on their diffusion, which makes it more challenging to estimate their effect on mortality.

We confront this challenge by using the timing of the discovery of sulfa drugs-when no other major factors are known to have affected mortality trends— combined with their rapid 
diffusion. These facts enable us to provide credible evidence on the impact of sulfa drugs on mortality despite the lack of data on diffusion. First, we test for structural trend breaks in the mortality time series. We test both whether the timing of the trend break lines up with the introduction of sulfa drugs and whether the trend break is statistically significant. For diseases treated with sulfa drugs (maternal mortality, ${ }^{1}$ pneumonia, and scarlet fever), we find evidence of trend breaks in the mortality series around 1937, the first year of large-scale sulfa drug production.

Our empirical strategy also uses another fact about sulfa drugs: from clinical trials conducted in the 1930s, we know that they were only effective against certain infectious diseases. We thus can also examine mortality trends for a major infectious disease that was not treatable with sulfa drugs, tuberculosis.We find no trend break during the relevant period for this “control disease.”

We estimate the magnitude of the effect of sulfa drugs on mortality using a difference-indifferences regression approach that compares mortality differences between treated and control diseases before and after 1937. Our estimates are based on the identifying assumption that post1937 mortality declines for treated diseases, beyond those that occurred for the control disease, are due to sulfa drugs. The results suggest that sulfa drugs were responsible for a $25-40 \%$ decline in maternal mortality, a $17-36 \%$ decline in pneumonia mortality, and a 52-67\% decline in scarlet fever mortality between the pre-1937 and post-1937 periods. ${ }^{2}$ These declines account for between $40 \%$ and $75 \%$ of total declines for these causes of death during this period. In addition,

\footnotetext{
${ }^{1}$ As shorthand, we call maternal mortality (death due to complications from childbirth) a disease, but it is more precisely a cause of death.

${ }^{2}$ Pneumonia (treatable with sulfa drugs) is combined with influenza (not treatable with sulfa drugs) in our mortality data, as explained in Section 3. When calculating the effect of sulfa drugs on pneumonia, we assume the sulfainduced decline in the combined category is due to a decline in pneumonia mortality.
} 
we find larger declines in urban areas, consistent with historical evidence that sulfa drugs diffused more rapidly in cities than in rural areas.

Finally we compare the effect of sulfa drugs on mortality for blacks and whites. Diffusion of sulfa drugs was likely slower among blacks, due to the inferior medical care available to them under segregation and to the high age of southern blacks living in rural areas (Douglas Almond, Kenneth Y. Chay, and Michael Greenstone 2006, Loudon 1992). More generally, it has been hypothesized that innovation benefits higher socioeconomic status (SES) groups first (Bruce G. Link, Mary E. Northridge, Jo C. Phelan and Michael L. Ganz 1998). Consistent with this hypothesis, we find that mortality from diseases treatable with sulfa drugs fell less for blacks than for whites.

The rest of the paper is organized as follows. The next section presents a brief history of sulfa drugs. In Section 3, we describe the data. Section 4 presents graphical evidence and tests for structural breaks. Section 5 estimates the magnitude of the effect of sulfa drugs on mortality. In section 6, we investigate racial differences in the effect of sulfa drugs. Section 7 concludes.

\section{History of sulfa drugs}

Sulfa drugs were the first effective antibacterial agents to be produced in a pharmaceutical laboratory. Before the first sulfa drug was synthesized in 1932, infectious disease research and treatment was dominated by immunotherapy, which involved the use of either animal serum containing antibodies to treat patients (passive immunization) or vaccines that prevent the occurrence of disease by triggering the body to produce antibodies (active immunization) (Loudon 2002). While serum was not widely used due to the high cost and the 
high risk of serum-related illness, several important vaccine discoveries were made in the late nineteenth century, including the rabies vaccine (1885) and the diphtheria antitoxin (1891).

In the late 1920s, German researchers began investigating the antibacterial potential of textile dyes (Loudon 1991). In 1932, Gerhard Domagk, a German scientist working at the chemical and dye company I.B. Farben, discovered that a red dye compound, "Prontosil," was successful in treating mice injected with streptococci. Domagk’s results, however, were not published until $1935 .^{3}$ That same year, the Pasteur Institute in France showed that the active ingredient in the dye compound was sulfonamide. The structure of sulfonamide had been documented in the doctoral dissertation of an Austrian chemist, Paul Gelmo, in 1908 and the patent on it had long expired. Therefore, the technology for making sulfonamide was available, and anyone could produce it. It was also relatively inexpensive to produce. As a result, production and clinical testing of sulfonamide began on a large scale soon after its discovery.

The first major clinical trial of sulfa drugs occurred in 1936 at Queen Charlotte’s Hospital in England when Prontosil was given to 38 women with serious cases of puerperal fever, a complication from childbirth caused by streptococcal infection that was the leading cause of maternal mortality at the time. The results, published in the June 1936 issue of the Lancet, reported a mortality rate of $8 \%$ among treated patients versus $24 \%$ among the most recent 38 untreated patients (Leonard Colebrook and Maeve Kenny 1936a). The success of sulfa drugs in treating puerperal fever was replicated, and even surpassed, in subsequent clinical trials in London, as well as in other parts of Europe (Colebrook and Kenny 1936b, M.A. Foulis and John B. Barr 1937; G. F. Gibberd 1937). Prontosil was first used in the U.S. in 1935 to treat a child with meningitis at Babies Hospital in New York (Andrew J. Schuman 2003). Further U.S. testing

\footnotetext{
${ }^{3}$ As a result of his discovery, Domagk was awarded the Nobel Prize in Physiology and Medicine in 1939, but due to
} the Nazi government's opposition to such a prize, was not able to accept the award until 1947 (Kiefer 2001). 
in 1936 at Johns Hopkins University and Western Pennsylvania Hospital showed that sulfa drugs were effective against scarlet fever and pneumonia (e.g., Perrin H. Long and Eleanor A. Bliss 1937). Over the next several years, clinical tests provided compelling evidence that various sulfa compounds were effective in treating puerperal fever, pneumonia, scarlet fever, meningitis, gonorrhea, and erysipelas (S.W. Sappington and G.O. Favorite 1939; Paul H. Hamilton 1938). ${ }^{4}$

The lay press created immediate and intense enthusiasm for the drugs. Sulfa drugs became widely-known in the U.S. following a December 1936 New York Times article reporting that Prontosil cured President Franklin D. Roosevelt's young son of a deadly streptococcal infection. By 1939, sulfa drugs were commonly referred to as 'magic bullets' and a 'growing miracle’ and credited with declines in mortality from childbirth, pneumonia, and other diseases. ${ }^{5}$

Pharmaceutical companies took advantage of the positive press on sulfa drugs. By as early as 1937, sulfa drugs were widely available and dispensed in the U.S. That year, output of sulfa drugs totaled 350,000 pounds; by 1940, it had doubled; and by 1942, production exceeded 14 million pounds (U.S. Tariff Commission, 1936-1950). More than 5000 sulfa compounds were developed by the early 1940s (though not all of them proved to be effective) (David M. Keifer 2001). Until 1938 sulfa drugs were available without a prescription, but physicians routinely prescribed them, and beginning in 1938, a prescription was required (Barron H. Lerner 1991). ${ }^{6}$

\footnotetext{
${ }^{4}$ For many clinical trials, particularly those involving diseases with high fatality rates, concurrent controls were not used for ethical reasons (Lerner 1991; Loudon 2002). In other cases where disease fatality rates were relatively low, definitive conclusions about the effect of sulfa drugs on mortality could not always be reached. Nonetheless, the successful results of repeated clinical testing were still viewed as compelling evidence of sulfa drugs' effectiveness. ${ }^{5}$ New York Times, April 9, 1939; New York Times, August 8, 1941, New York Times, July 19, 1942; New York Times, April 4, 1940.

${ }^{6}$ In 1937, 100 people died from consuming an "Elixir of Sulfanilamide”, an untested liquid sulfa preparation. This incident led to the passage of the 1938 Federal Food, Drug, and Cosmetic (FDC) Act that mandated safety testing of drugs before marketing and prohibited the sale of some non-narcotic drugs without a prescription, including sulfa drugs. Sulfapyridine, a sulfa compound, was the first important new drug to be reviewed under the FDC Act (Lesch 2007).
} 
The rapid diffusion of sulfa drugs was aided by their low price, about $\$ 35$ to $\$ 100$ (2009 dollars) per patient for a full course of the life-saving medicine. ${ }^{7}$

The fact that sulfa drugs were a sensation and quickly became widely available is very useful for analyzing their effects. These characteristics of sulfa drugs' diffusion allow us to look for sudden changes in outcomes (i.e., mortality) right after sulfa drugs were discovered and entered into mass production. This approach would be inappropriate for a medical technology with more gradual adoption, since one could not demarcate a before and after period as sharply.

The subsequent development of penicillin and other antibiotics have largely overshadowed the revolutionary effect of sulfa drugs on medical practice and research. However, the ten-year period covering the discovery and widespread use of sulfa drugs was considered 'epochal' at the time, and sulfa drugs are credited today with ushering in a 'therapeutic revolution’ (Long and Bliss 1939:1; Richard M. Weinshilboum 1987:1). Sulfa compounds are still used today, but have been largely replaced by antibiotics, which proved to be more effective and less toxic in the treatment of most infectious diseases. ${ }^{8}$

\section{Data and disease selection}

For our analyses, we use U.S. vital statistics data collected at the national-, state-, and city-level for the period from 1920 to 1950 . Data prior to 1930 by state and disease were collected by Grant Miller and made publicly available through the National Bureau of Economic Research. ${ }^{9}$ We collected additional state-level mortality data from 1930 to 1950 on four causes

\footnotetext{
${ }^{7}$ The calculation is based on revenue, production volume, and number of patients treated in 1943, as reported by Lesch (2007). As a cross-validation, another price estimate is $\$ 4.30$ per patient per day (converted to 2009 dollars), suggesting the drugs were taken an average of 8 to 23 days.

${ }^{8}$ Today, sulfa drugs are used to treat some antibiotic-resistant infectious diseases, but are more commonly used in the treatment of urinary tract infections, leprosy, and fungal diseases.

${ }^{9}$ See http://www.nber.org/data/vital-statistics-deaths-historical/.
} 
of death that were shown to be highly responsive to sulfa drugs in clinical trials: maternal mortality, pneumonia, scarlet fever, and meningitis. In our analysis, we refer to these four causes of death as "treated" diseases. The most common cause of maternal mortality, responsible for roughly $40 \%$ of maternal deaths in the mid-1930s, was puerperal fever (also called puerperal sepsis), caused by streptococcus bacteria, which was responsive to sulfonamide; therefore, we use maternal mortality as a proxy for death from puerperal fever (Loudon 1988). In 1939, influenza, which was not affected by sulfa drugs, was combined with pneumonia into a single category in the vital statistics volumes. In order to achieve a consistent data series, we use the combined pneumonia/influenza category for all years. For the years when disaggregated data are available, pneumonia accounts for about $75 \%$ of total deaths in the combined category. To calculate state-level death rates, we use population data from the Census Bureau's decennial censuses from 1920 to 1950 . For years between censuses, we estimate the population by linear interpolation within a state.

We also use data on comparison diseases, that is, diseases untreatable with sulfa drugs. An ideal comparison disease would be an infectious disease that is similar to the infectious diseases treated with sulfa drugs, with the exception that it does not respond to any sulfa compound. The disease that meets this criterion is tuberculosis, which we loosely refer to as our “control” disease (Karl H. Pfuetze 1945). ${ }^{10}$ We also collected data on three chronic diseases: diabetes, heart disease, and cancer. While chronic diseases are clearly very different from the infectious diseases treated with sulfa drugs, they can provide some insight into whether there were other factors that affected mortality rates for all diseases during the period when sulfa drugs were introduced.

\footnotetext{
${ }^{10}$ An additional criterion is the availability of a consistent data series for the time period studied. For example, influenza would have been a possible control disease had it not been combined with pneumonia in the vital statistics data.
} 
In addition to the state-level data, we use national-level data. Age-standardized national mortality series (using the 1940 population as the standard) are available in vital statistics volumes, except for scarlet fever mortality and maternal mortality. For scarlet fever, we aggregated age-specific deaths at the state level and then calculated national age-adjusted mortality rates using the same direct method of standardization to the 1940 population. Our analysis examines the maternal mortality ratio (maternal deaths per 100,000 live births) rather than maternal mortality rate (maternal deaths per 100,000 women of reproductive age), as the maternal mortality ratio (MMR) is the conventional measure of maternal mortality. The national MMR is constructed by aggregating total deaths and total births from state-level data and then calculating the ratio. ${ }^{11}$

The U.S. death registration system did not include all states until 1933. Therefore, pre1933 national mortality estimates are approximations to complete national rates and, for our state-level analysis, the number of data points available for each state varies. ${ }^{12}$ The state results presented are based on unbalanced panel data, but our results are very similar when we restrict our analysis to states with complete data series. For the regression sample, we use 1925 as the beginning of our sample period to minimize the imbalance. The end date for the regression sample is 1943; beyond this date, the introduction of other medical advances in the mid-1940s would be a confounding factor.

The city-level mortality data were collected by Thomasson and Treber (2008). These data have two limitations for our purposes: (1) they cover only 1928 to 1940, and (2) they contain information on maternal mortality but not other causes of death. During the relevant period,

\footnotetext{
${ }^{11}$ Following convention, the MMR is not age-adjusted. The MMR is preferable to the maternal mortality rate as a measure of risk because it represents the risk of death once a woman has become pregnant.

${ }^{12}$ The annual collection of mortality statistics, known as the death registration system, began in 1900 . The death registration area expanded from 10 states in 1900 to 36 states in 1920 and the entire United States by 1933. Alaska, Hawaii and the District of Columbia are not included, so there are at most 48 states in a given year.
} 
maternal deaths were reported at the city level for each city with a population of at least 10,000 (in states that had entered the death registration system). We focus our analysis on larger cities with populations of at least 25,000 (as of 1930), of which there are 267.

Table 1 shows age-adjusted national mortality rates for 1920 and 1950. It also reports summary statistics for the 1925-36 pre-sulfa period and 1937-43 post-sulfa period used in our regression analyses. The state means are not an exact match to the national data because the national data series are age-adjusted and because the state averages are not population-weighted.

In 1920, the MMR in the U.S. was about 809 deaths per 100,000 live births, much higher than in Western Europe, where the MMR ranged from 235 in Denmark to 665 in France (Loudon 1988). The 1920 MMR level in the U.S. is similar to levels found in developing countries such as Chad and Ethiopia today (Loudon 1988, WHO et al. 2004). The MMR declined by roughly $45 \%$ between the pre-sulfa and post-sulfa periods; similarly large declines occurred in Western Europe. The pneumonia/influenza and tuberculosis disease categories were responsible for the largest share of infectious disease deaths between 1920 and 1950 and accounted for approximately 22\% of overall mortality. Deaths due to scarlet fever and other infectious diseases were much less common. Mortality for the infectious diseases considered here dropped by $34 \%$ to $68 \%$ between the pre- and post-sulfa period.

\section{The effect of sulfa drugs on mortality in the U.S.: Graphical and time-series evidence}

Ideally, to estimate the impact of sulfa drugs on mortality, one would estimate an equation such as the following:

$$
\log (M)_{i t}=\beta_{0}+\beta_{1}(\text { Sulfa drug availability })_{i t}+e_{i t}
$$


The dependent variable is the natural $\log$ of the mortality rate in medical market $i$ and year $t .^{13}$ The independent variable would be a measure of sulfa drug availability (supply) that is uncorrelated with the demand for sulfa drugs. The hypothesis is that when sulfa drugs become more available, mortality falls $\left(\beta_{1}<0\right)$. In practice, researchers might define the medical market as a state and use state-year level data on sales volume or the number of prescriptions issued as a proxy for sulfa drug availability, but it is worth keeping in mind that such a regression would suffer from endogeneity bias. For example, sales of sulfa drugs are likely to be higher in places with higher mortality risk from sulfa-treatable diseases. There is also a data limitation in our case: there are no data on the availability of sulfa drugs disaggregated by state or other subgroups for the period examined.

Instead, we use two facts about sulfa drugs to arrive at empirical tests of their effects. First, we use the fact that the timing of the sulfa drug discovery can be taken as exogenous and that, because sulfa drugs could not be patented, diffusion was rapid: the first year of large-scale production and sales of sulfa drugs in the U.S. was 1937 (U.S. Tariff Commission, 1936-1950). This allows us to use time series techniques to test whether the timing of mortality declines corresponds to sulfa drugs’ introduction in 1937. Second, there is strong evidence from clinical trials that sulfa drugs were effective against some infectious diseases but not others. Therefore, we are able to use infectious diseases that were impervious to sulfa compounds as a comparison group in our analysis, netting out the effects of other factors that may have coincidentally lowered mortality around 1937.

\footnotetext{
${ }^{13}$ The reason for modeling the log of the mortality rate is that medical advances are hypothesized to have a proportional change on mortality rates: if the initial rate of mortality is high, there is more room for mortality decline, so a medical advance should lead to a larger drop in the level of mortality than if the initial rate is low. Using proportional changes also facilitates comparisons of mortality change across diseases that have different levels of mortality initially.
} 
Most medical innovations do not have the fortuitous characteristics that the discovery of sulfa drugs has—-that is, fortuitous from the empirical researcher's point of view. Penicillin was a revolutionary medical advance, but it was invented in the 1940s at the same time as other major medical advances (e.g., blood transfusions, refinements in sulfa drugs, and anti-malarial pesticides), which makes isolating its impact difficult. Moreover, there seems to be no control disease available, that is, an infectious disease that was unaffected by penicillin or by other contemporaneous innovations. Hence, we examine the effects of medical innovation in the early $20^{\text {th }}$ century by focusing on sulfa drugs both because sulfa drugs were an important breakthrough and because other breakthroughs like penicillin do not lend themselves well to an impact analysis using population data.

\section{Graphical evidence on trend breaks in the mortality time series}

Figure 1 plots total mortality between 1920 and 1950, and Figure 2, mortality for the four sulfa-treated diseases: maternal mortality, pneumonia/influenza, scarlet fever, and meningitis. ${ }^{14}$ All graphs show mortality on a log scale. The vertical line at 1937 indicates the first year of large-scale production of sulfa drugs in the U.S. With the exception of meningitis, the mortality curves for the treated diseases become noticeably steeper after 1936-7.

Meningitis has a very different pattern than the other diseases, with wide fluctuations that suggest outbreaks. Modeling this type of time-series process requires very different techniques than those we use for the rest of the diseases in this study, and for this reason we do not pursue meningitis further in our analysis.

\footnotetext{
${ }^{14}$ Graphs are based on national-level age-adjusted death rates, using 1940 as the standard, except in the case of MMR, which is based on aggregated state-level data.
} 
The mortality rate for pneumonia/influenza also fluctuates in the early years, driven by outbreaks of influenza (Neil M. Ferguson, Alison P. Galvani, and Robin M. Bush 2003, E. Lofgren, N. Fetterman, Y.N. Naumov, et al 2007). We will be testing the hypothesis that sulfa drugs affected pneumonia mortality, not influenza mortality (as noted earlier, influenza was unaffected by the drugs), so the volatility of influenza mortality is, in effect, noise in our data. As it affects the dependent variable, this noise will make our pneumonia/influenza results less precise, but is otherwise not problematic.

In contrast to the treated diseases, mortality trends for the control and chronic diseases (Figures 3 and 4) do not show any noteworthy changes around the time that sulfa drugs were introduced. Death rates for our control disease, tuberculosis, are trending downward and chronic diseases trending upward, with no obvious breaks in the trend lines around 1937, suggesting there were no factors other than sulfa drugs affecting mortality at this time. ${ }^{15}$ Since tuberculosis constitutes a closer comparison group than chronic diseases, for brevity, we exclude the chronic diseases from the remainder of our analysis.

The graphs also show that between 1935 and 1937 there is a slight increase in overall mortality as well as mortality from several of the specific causes of death considered here. The cause of this uptick is a puzzle in the demographic literature and one that we do not attempt to solve in this paper. Its timing is somewhat unfortunate for our purposes since we are interested in structural breaks in our mortality series around 1937; however, this uptick exists in the mortality series for both treated and control diseases (and, to a lesser extent, for chronic diseases). To

\footnotetext{
${ }^{15}$ The decline in tuberculosis appears to steepen around 1945. Penicillin and other antibiotics effective against tuberculosis were introduced around this time.
} 
ensure that our results are not driven by this anomaly, we also check the robustness of our results to the omission of these years in our estimation. ${ }^{16}$

\section{Formal tests of trend breaks in mortality time series}

The graphs provide visual evidence that mortality declines accelerated when sulfa drugs were introduced in 1937. We next conduct a more formal test for structural breaks in the mortality series. Using out-of-sample information that large-scale production of sulfa drugs began in 1937, one could assume that 1937 is the first year that sulfa drugs would affect mortality and examine whether there is a statistically significant break for that year. We start with a stronger test that does not assume knowledge of when the trend break occurs. We test whether, among all possible break dates, the break is strongest in a statistical sense in or around 1937 and whether the break is statistically significant.

We test for a trend break in year $\tau$ using the following model:

$$
\log (M)_{t}-\log (M)_{t-1}=\alpha+\delta_{0} D_{t}(\tau)+e_{t}
$$

The dependent variable, $\log (M)_{t}-\log (M)_{t-1}$, is the first difference of log mortality, and $D_{t}(\tau)$ is an indicator variable equal to zero for all years before $\tau$ and equal to one for all subsequent years. In using first differences, we are testing for a trend break rather than level change in mortality at year $\tau .^{17}$ To account for serial correlation, we compute Newey-West standard errors and allow the error structure to be correlated up to two lags.

\footnotetext{
${ }^{16}$ For all diseases except pneumonia/influenza, the data suggest that the mortality uptick is limited to 1935 to 1936. For pneumonia/influenza, the uptick is between 1935 and 1937. To be conservative, we present results from models that exclude 1935 to 1937 as our main robustness test. Appendix Table A1 presents results from an alternative test that excludes only 1935 and 1936. In both cases, dropping the years of the uptick has little impact on our results.

${ }^{17}$ The graphs suggest a break in the trend rather than level. Moreover, break tests require the data to be stationary, which the non-differenced mortality series do not satisfy. Using both Pierre Perron's 1989 test and Augmented Dickey Fuller tests, we fail to reject non-stationarity when using levels rather than differences. Results available upon request.
} 
Using national mortality data for 1920 to 1950, we test for a possible break in each year in the interval 1933 to 1942; that is, we estimate equation (4.2) ten times, with $\tau$ taking on each value between 1933 and 1942. The interval of possible break dates is smaller than the full span of the data because one needs an adequate number of data points before (after) the earliest (latest) break point to estimate the regression line before and after the break point. ${ }^{18}$ For each estimate, the null hypothesis of no trend break, or $\delta_{0}=0$, is tested, and the largest of the resulting F-statistics is used to determine the best possible break point and the significance of the break. ${ }^{19}$ We interpret finding a trend break in or around 1937 as evidence that the introduction of sulfa drugs had an impact on mortality.

Table 2 presents the results of the trend-break test, which confirm the visual evidence. For each of the treated diseases, the test identifies a structural break in 1937 or $1938 .^{20}$ The three treated diseases account for about $12 \%$ of total mortality in the pre-period and they were not the only diseases treated with sulfa drugs, so it is perhaps not surprising that total mortality also shows a possible trend break in 1937. The short time series leads to relatively low statistical power, but the trend breaks in 1937 are statistically significant at the $1 \%$ level for MMR and scarlet fever. In contrast, for the control disease, tuberculosis, the test identifies 1942 as when a trend break possibly occurs (statistically insignificantly).

\footnotetext{
${ }^{18}$ There is little guidance in the literature on how to choose the appropriate test window. A common approach is to trim 15\% from both ends. However, in the case of small samples such as ours, that would leave only three data points on either side of the test window.

${ }^{19}$ This test is the Quandt Likelihood Ratio test, which is, in essence, a sequential Chow Test where the largest F-test from these sequential tests is used to identify a possible break point (Richard E. Quandt 1960). We use Andrews $(1993,2003)$ critical values that account for the fact that many possible break points are being tested and, therefore, there are many chances to reject the null hypothesis of no structural change (Stock and Watson, 2003).

${ }^{20}$ The later break date (1938) for pneumonia/influenza mortality likely reflects the availability of sulfapyridine, a new sulfa compound more effective in treating pneumonia, beginning in 1938 (Lesch, 2007).
} 


\section{Regression estimates of the effect of sulfa drugs on mortality}

This section uses regression analysis to measure the magnitude of the effect of sulfa drugs on mortality. Based on the trend-break results above plus out-of-sample knowledge that 1937 was the first year of widespread sulfa use, the regression analysis interprets post-1937 changes in mortality for the treated diseases as the effect of sulfa drugs. We estimate two models, one that allows for a level change in mortality in 1937 and one that allows for both a level change and slope change in $1937 .{ }^{21}$

Post-1937 changes in mortality

Using the national mortality series from 1925 to 1943 (19 observations), we first estimate a simple model that allows mortality to be a function of an overall linear time trend and a level shift in 1937:

$$
\log (M)_{t}=\beta_{0}+\beta_{1} \text { Year }_{t}+\delta_{0} \text { Post-1937+e } e_{t}
$$

The dependent variable, $\log (M)_{t}$, is the log of mortality in year $t$, Year ${ }_{t}$ is a continuous year variable, and Post-1937 $t$ is a dummy variable equal to one if the year is 1937 or after. The question of interest is whether the coefficient on the post-1937 dummy $\left(\delta_{0}\right)$ is negative and significant.

We also estimate a trend-break model that allows for a change in the slope after 1937:

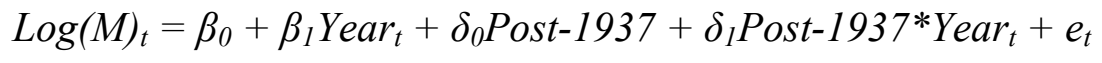

\footnotetext{
${ }^{21}$ The time-series tests in the previous section required stationary time series, and because our mortality data are only stationary once they are first-differenced, we tested for trend breaks using first-differenced data and could not test for level shifts. The analysis in this section does not require stationarity, so we are able to estimate both level and slope changes.
} 
In this model, we are interested in whether $\delta_{0}$ and $\delta_{l}$ are negative and significant. In both models, to account for serial correlation we compute Newey-West standard errors that allow the error structure to be correlated up to two lags.

The first model (equation 5.1) is more parsimonious, which might be preferable given the short time series; there is limited statistical power to estimate slope changes with a short panel. However, the second model (equation 5.2) allows for the possibility that the effect of sulfa drugs starts off small and then accelerates, which one might expect given that technology adoption is not instantaneous. Indeed, the visual evidence in Figure 2 is consistent with sulfa drugs accelerating mortality declines and not just causing a one-time drop. ${ }^{22}$ We present results from both models, but the slope-change model is our preferred specification.

The results in the first column of Table 3 (based on estimating equation 5.1) suggest that there was a decline in all-cause mortality after 1937, but the coefficient is not statistically significant. However, column 2 (based on equation 5.2) shows that there is a negative and statistically significant change in the slope after 1937. The coefficient in column 1 suggests that age-adjusted mortality fell by about 2\% between the pre-1937 period (1925-36) and the post1937 period (1937-1943). The coefficients from column 2 indicate a larger effect of about 4\%. The total effect size from equation 5.2 is computed as $\delta_{0}+3.5 * \delta_{1}$, where the factor of 3.5 is the average value of Year for our seven years of post-1937 data.

Table 3 also shows that each of the three diseases treatable with sulfa drugs saw significant declines in mortality after 1937. The coefficients of interest are negative and significant for each disease and for both specifications, expect for pneumonia/influenza for

\footnotetext{
${ }^{22}$ When we estimate the post-1937 decline in mortality non-parametrically, by including a dummy for each year starting in 1937 (in addition to a year trend), the results suggest that the second model (equation 5.2) describes the time pattern in the effect of sulfa drugs well. The coefficients suggest that the effect of sulfa drugs was increasing linearly and stabilized around 1942. For MMR, the coefficients suggest that the effect may have been increasing faster than linearly in the first few years after 1937. Results available upon request.
} 
which the intercept, although negative, is not statistically significant. The coefficients suggest a decline in maternal mortality of 26 to $41 \%$, in pneumonia/influenza mortality of 15 to 29\%, and in scarlet fever mortality of 58 to 75\%. (The larger effects are always from (5.2).) On the other hand, the coefficients for the 1937 break are positive and statistically insignificant for tuberculosis, our control disease.

\section{Difference-in-difference estimates}

Next, we estimate difference-in-difference models that compare pre- and post-1937 levels and trends between treated diseases and the control disease. The inclusion of tuberculosis as a control disease accounts for any other factors that may have affected mortality around 1937 . We

allow each disease to have its own overall linear trend, so the identifying assumption is that, conditional on disease-specific trends, any pre- versus post-1937 changes in mortality caused by factors besides sulfa drugs are the same for the control and treated diseases, and that sulfa drugs are the only factor differentially affecting the treated diseases beginning in 1937.

We start by presenting results using national level data, examining each treated disease separately. We stack the data so that there are two observations per year, one for the treated disease and one for the control disease. We then estimate two models,

$$
\begin{aligned}
& \text { (5.3) } \log (M)_{d t}=\beta_{0}+\beta_{1} \text { Treated }_{d} * \text { Post }-1937_{t}+\beta_{2} \text { Treated }_{d} * \text { Year }_{t}+\beta_{3} \text { Treated }_{d}+ \\
& \beta_{4} \operatorname{Year}_{t}+\varepsilon_{d t}
\end{aligned}
$$

and

$$
\begin{aligned}
(5.4) \log (M)_{d t}= & \beta_{0}+\beta_{1} \text { Treated }_{d} * \text { Year }_{t} * \text { Post }-1937_{t}+\beta_{2} \text { Treated }_{d} *{\text { Post }-1937_{t}}+ \\
& \beta_{3} \text { Treated }_{d} * \text { Year }_{t}+\beta_{4} \text { Treated }_{d}+\beta_{5} \text { Year }_{t}+\varepsilon_{d t} .
\end{aligned}
$$


The dependent variable is the log of the mortality rate for disease $d$ and year $t$. Treated $_{d}$ is an indicator variable for whether disease $d$ is a treated disease, Post-1937 $t$ is an indicator variable equal to zero for $t$ between 1925 and 1936 and equal to one for the period 1937 to 1943, and Year $_{t}$ is a continuous year variable (centered on 1937). Robust standard errors are reported.

The first model (equation 5.3) examines changes in the level of the dependent variable after 1937. The coefficient of interest, $\beta_{1}$, measures whether the post-1937 reduction in mortality was larger for treated diseases than for the control disease. The second model (5.4) allows for a change in both the intercept and the slope after 1937. In this model, the statistical question of interest is whether $\beta_{1}$ and $\beta_{2}$ are jointly significantly different from zero. Both models allow for a different linear time trend for treated and control diseases.

We also present results using state-level data. The coefficients should be similar to those obtained with national-level data (except for the age-adjustment and the population weighting), but using state-level data can increase the precision of the estimates since we can control for state-level covariates (e.g., state-specific trends) that affect mortality but are orthogonal to our variables of interest. We estimate the following equations with state-level data:

$$
\begin{aligned}
& \text { (5.5) } \log (M)_{\text {idt }}=\beta_{0}+\beta_{1} \text { Treated }_{d} * \text { Post-1937 }_{t}+\beta_{2} \text { Treated }_{d} * \text { Year }_{t}+\beta_{3} \text { Treated }_{d}+ \\
& \beta_{4} \text { Year }_{t}+\gamma_{i t}+\varepsilon_{i d t}
\end{aligned}
$$

and

(5.6) $\log (M)_{i d t}=\beta_{0}+\beta_{1}$ Treated $_{d} *$ Year $_{t} *$ Post-1937 $+\beta_{2}$ Treated $_{d} *$ Post-1937 +

$$
\beta_{3} \text { Treated }_{d} * \text { Year }_{t}+\beta_{4} \text { Treated }_{d}+\beta_{5} \text { Year }_{t}+\gamma_{i t}+\mu_{i t} * \text { Year }_{t}+\varepsilon_{\text {idt }} \text {. }
$$

The dependent variable is the log of the mortality rate in state $i$ for disease $d$ and year $t$, and Treated, Post-1937 and Year are defined as before. The equations now include State*Post-1937 fixed effects, denoted by $\gamma_{i t}$, which control for the main effect of Post-1937 and absorb state 
variation in mortality declines (which is orthogonal to the regressor of interest, but adds noise to the estimates), and State*Post-1937 fixed effects interacted with Year ${ }_{t}$, denoted by $\mu_{i t}{ }^{*}$ Year $_{t}$. Standard errors are clustered by disease-year, since the variable of interest only varies at this level. $^{23}$

We estimate the equations separately for each treated disease using mortality data from 1925 to 1943. Table 4, Panel A presents the results of our main specification for the national data. Panel B shows the results using state-level data. As expected, the coefficients are of similar magnitude, but the standard errors are somewhat smaller using the state data. The coefficients of interest are negative and significant using both levels of data and for all three treated diseases (except for $\beta_{1}$ for pneumonia/influenza, which is negative but not significant). These results suggest that the introduction of sulfa drugs led to significant mortality declines for diseases that were treatable with the new drugs.

Panel C shows that the results are robust to the exclusion of 1935 to 1937, the years of the uptick in mortality (we present these using the state-level data for brevity). While the estimated coefficients in the MMR and scarlet fever models are virtually unchanged, the coefficients in the pneumonia/influenza model are reduced by roughly a half. That the pneumonia/influenza point estimates are sensitive to excluding even a few points is not surprising given that the data are noisier for this outcome and we have a short panel. In all other cases, however, the estimates are negative and statistically significant.

We can use the difference-in-differences coefficients to assess the magnitude of sulfa drugs' effect on mortality. Starting with the first model (equation (5.5), using the coefficients reported in Panel B, column 1), the MMR coefficient of -0.28 implies that the introduction of

\footnotetext{
${ }^{23}$ We also estimated standard errors clustering by state to correct for possible serial correlation (Marianne Bertrand, Esther Duflo, and Sendhil Mullainathan 2004). When we cluster by state, the standard errors are actually smaller than when we estimate robust standard errors, suggesting that this serial correlation correction is not needed.
} 
sulfa drugs resulted in a 25\% decrease in MMR in the post period, or $163(0.25 * 653)$ fewer maternal deaths per 100,000 births between 1925-36 and 1937-43. Sulfa drugs thus appear to explain 56\% of the total decline in MMR during this time period, which fell by about 292 deaths per 100,000 births between the two periods (Table 1). The estimates also suggest that sulfa drugs were responsible for a 13\% decline in pneumonia/influenza mortality (a decrease of 15 deaths per 100,000 people) and 39\% of total mortality decline in this disease category. If one assumes the averted deaths in the combined pneumonia/influenza category were from pneumonia, then sulfa drugs caused a 17\% decline in pneumonia mortality. Finally, the scarlet fever results imply that sulfa drugs led to a $52 \%$ drop in scarlet fever mortality, which accounts for $76 \%$ of the total decline in this cause of death between the pre-1937 and post-1937 periods.

The coefficients from the second model, which allows for a break in trend as well as a level change (Panel B column 2), suggest larger effects: MMR declined by 40\%, pneumonia/influenza declined by 27\% (implying a 36\% decline in pneumonia) and scarlet fever declined by $67 \%$. These effect sizes are very similar to those we obtained using the simple difference estimates in the previous subsection.

Our estimates are quite consistent with clinical trial estimates from the time (G.M. Evans and Wilfrid F. Gaisford 1938, Colebrook and Kenny 1936a). In clinical trials, sulfa drugs reduced mortality from pneumonia by 50 to $70 \%$, while we estimate a $17 \%$ to $36 \%$ decline at the population level. The larger effect size in clinical trials is not surprising since only a portion of the population afflicted with pneumonia took sulfa drugs, and drugs are generally more efficacious in a controlled, clinical setting. Sulfa drugs reduced mortality from puerperal fever, which was responsible for roughly $40 \%$ of maternal deaths in the pre-sulfa period, by about $81 \%$ in clinical trials, implying a 32\% reduction in maternal mortality. In comparison, we find a 
maternal mortality decline of $25 \%$ to $40 \%$. It is somewhat surprising that the population-level effect for maternal mortality is the same size as the clinical-trial effect, but one potential explanation is that, because the vast majority of births were physician-assisted, sulfa drugs were administered in a high proportion of puerperal fever cases in the general population (higher than for pneumonia cases, where a physician may not always have been consulted). ${ }^{24}$ For scarlet fever, we do not have estimates from clinical trials to compare with our results.

Using the estimated effect sizes combined with the summary statistics presented in Table 1, we can calculate the contribution of sulfa drugs to the overall mortality decline from 1937 to 1943. We first convert the decline in MMR due to sulfa drugs to a percent decline in maternal deaths per 100,000 individuals, which we estimate to be $24 \%$. We know that mortality from maternal causes, pneumonia/influenza, and scarlet fever accounted for $1.1 \%, 10.5 \%$, and $0.2 \%$, respectively, of total deaths in the pre-sulfa period. Therefore, we estimate that sulfa drugs, through their effect on the three treated diseases, were responsible for $1.7 \%$ of overall mortality decline between $1925-36$ and $1937-43(0.24 * 0.011+0.13 * 0.105+0.52 * 0.002)$. If we repeat the calculation using the second model, we find an overall effect on mortality of $4.1 \%$. These estimates are very similar to the simple post-1937 change in all-cause mortality implied by Table 3.

The impact of sulfa drugs on life expectancy can be estimated with a back-of-theenvelope calculation. Using national-level mortality counts by age (and by cause) for 1936 along with population estimates, we can compute actual life expectancy in 1936. We can then calculate a counterfactual life expectancy using the lower mortality rates caused by sulfa drugs for the treated diseases. We find that sulfa drugs increased life expectancy by 0.38 to 0.76 years of life

\footnotetext{
${ }^{24}$ Another possible explanation is that, given that maternal deaths are difficult to classify, puerperal fever may have accounted for a larger share of maternal deaths than the $40 \%$ figure we assume.
} 
(the larger estimate uses results from the second model). Published estimates suggest that life expectancy increased by about 4.8 years during this period (from 58.5 to 63.3 between 1936 and 1943), so sulfa drugs account for $8-16 \%$ of the increase. Note that our estimates do not capture the full impact of sulfa drugs on life expectancy because we cannot account for the effects of sulfa drugs on mortality declines after 1943 and because, due to data limitations, we do not study the effect on other diseases (such as meningitis, erysipelas, and cerebrospinal fever) that sulfa drugs also treated. ${ }^{25}$

\section{Urban-rural evidence on maternal mortality}

While the above analysis provides strong suggestive evidence that the introduction of sulfa drugs caused a reduction in mortality starting in 1937, we conduct an additional test to validate our interpretation that the decline was due to sulfa drugs. Studies of diffusion of medical technology in the U.S. find that large, urban-based research hospitals are usually the first to adopt new medical technologies, followed, after the importance of the new technology is proven, by urban medical facilities and, lastly, by medical centers in rural areas, often after a considerable delay (Duke University, Medical Technology Assessment Working Group, 2006). According to historical accounts, clinical testing for sulfa drugs was first carried out at several urban-based research facilities in the U.S. such as Johns Hopkins University (Baltimore), Babies Hospital (New York City), and Western Pennsylvania Hospital (Pittsburgh). Therefore, one validation test is to compare post-1937 mortality reductions in urban and rural areas, with the expectation that urban areas would benefit from sulfa drugs more immediately than rural areas.

\footnotetext{
${ }^{25}$ Clinical trials also indicate that sulfa drugs reduced morbidity from pneumonia and our other treated diseases. They were also were effective in the treatment of various infections with low fatality rates, including bacillary dysentery and gonorrhea. Therefore, the contribution of sulfa drugs to health is greater than what is captured by focusing on mortality alone.
} 
We have urban-only mortality data but not rural-only data. Therefore, we compare urban mortality to state-level mortality, where state-level data represent the sum of mortality in urban and rural areas. If the trend breaks are larger in urban areas than in rural areas, then the urban data should show larger trend breaks than the state-level data that aggregate across urban and rural populations.

We restrict the urban data to cities with populations of at least 25,000 for two reasons. First, our hypothesis of a higher rate of diffusion in urban areas is more likely to hold in larger cities. Second, vital statistics data were not collected in cities smaller than 25,000 people in 1931 and 1932. Recall that our city-level data series includes maternal mortality only, and only covers the period from 1928 to 1940. Figure 5, which is based on city- and state-level data, shows that the MMR was higher in cities than at the state level until 1936, after which point an urban advantage emerges. While the mortality curves for both cities and states become noticeably steeper around 1936-7, the graph suggests that this slope change occurs earlier in cities.

Because the city-level series end in 1940, we cannot estimate the timing of trend breaks using the time series methods used above, which require a longer panel. We can, however, estimate regression models that test whether there is a larger break in urban areas in 1937, using pooled city- and state-level maternal mortality data. (An observation is either a state-level or a city-level mortality rate. States with more than one large city will have more than two observations in a given year). We estimate the following two regressions:

and

$$
\begin{aligned}
& \log (M M R)_{i c t}=\beta_{0}+\beta_{1} \text { Urban }_{c} * \text { Post-1937t }_{t}+\beta_{2} \text { Urban }_{c}+\beta_{3} \text { Urban }_{c} * \text { Year }_{t}+\beta_{4} \text { Year }_{t} \\
& +\gamma_{i t}+\varepsilon_{i c t}
\end{aligned}
$$

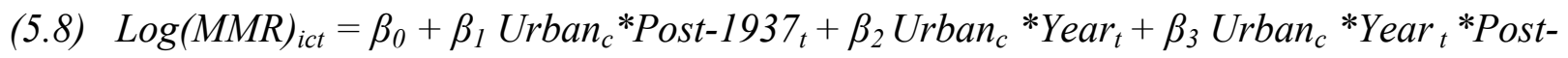

$$
1937_{t}+\beta_{4} \text { Urban }_{c}+\beta_{5} \text { Year }_{t}+\gamma_{i t}+\mu_{i t}{ }^{*} \text { Year }_{t}+\varepsilon_{i c t} \text {. }
$$


The dependent variable is the $\log$ of the maternal mortality ratio for geographic category $c$ (cityor state-level observation) in state $i$ in year $t$, Urban is an indicator variable for whether the observation is a city, Post-1937 is an indicator variable equal to zero in the period from 1928 to 1936 and equal to one in the period from 1937 to 1940, and Year $_{t}$ is a continuous year variable. Equation (5.7) includes State*Post-1937 fixed effects and allows for differential time trends in urban areas. Equation (5.8) also includes State* Post-1937 fixed effects interacted with Year. These equations are analogous to those used before, with the treated-disease dummy replaced with an urban dummy. The hypothesis is that the interactions with Urban and Post-1937 should be negative ( $\beta_{1}$ in Equation (5.7) and both $\beta_{1}$ and $\beta_{3}$ in Equation (5.8)). As the state-level data are an aggregate of data from cities and from rural areas, the error terms will be correlated across the state-level and city-level observations within a given state and year. Therefore, we cluster the standard errors by state-year.

Table 5 presents the regression results. For both equations, $\beta_{1}$ is negative and significant, suggesting that cities experienced statistically significantly larger declines in maternal mortality after 1937 compared to rural areas. In addition, in the second model, the slope of the MMR curve after 1937 is more negative in urban areas ( $\beta_{3}$ is negative and significant), suggesting that

mortality started to decline faster in cities compared to rural areas after sulfa drugs were introduced. Panel B again shows that, although the magnitude of these effects changes when the 1935-1937 years are excluded, the substantive conclusions of the analysis do not.

\section{Racial differences in the effect of sulfa drugs}

We next compare the effect of sulfa drugs for whites and blacks. A growing literature posits that new medical technologies may increase inequalities in health because they tend to 
favor, at least initially, the better off who are more able to access and implement health-related innovations (Sherry Glied and Adriana Lleras-Muney 2008, Dana P. Goldman and Darius N. Lakdawalla 2005). More broadly speaking, this idea is the basis of the "fundamental causes" hypothesis, which posits that socioeconomic (SES) gradients in health arise because those with higher SES use their greater resources to improve their health (Link et al 1998).

There are specific reasons to believe that sulfa drugs may have diffused more rapidly within the white population. During this period, the majority of blacks lived in lower-income Southern states and in predominantly rural areas, often at far distances from hospitals and physicians. Hospital segregation policies and greater resources in white facilities further contributed to lower health care utilization among blacks (Almond et al., 2006).

In addition, with regard to maternal mortality, the rate of home deliveries by untrained midwives was still high among black women (and very low among white women) living in the South during this period, which may have reduced black mothers' access to sulfa drugs during and after delivery (Loudon 1992, Almond et al. 2006). Thomasson and Treber (2008) find that in U.S. cities, greater rates of hospital births were associated with significant and large declines in MMR for both races after the introduction of sulfa drugs in 1937, but that the effect of hospitals on MMR in the post-sulfa period was greater for blacks than whites. This may reflect the relatively worse hospital care received by black mothers in the pre-sulfa drug period. ${ }^{26}$

If sulfa drugs diffused more rapidly among whites then blacks, then one should observe larger and steeper declines in mortality for whites than blacks after sulfa drugs' introduction in 1937. Figure 6 shows mortality by race for our treated and control diseases from 1920 to 1950.

\footnotetext{
${ }^{26}$ In their balanced city panel, Thomasson and Treber (2008) find that greater hospitalization of births in the pre1937 period lowered MMR for whites only, but the effect was larger in the post-1937 period. However, in their unbalanced panel, the mortality effects of hospital-based deliveries in the pre-sulfa drug period are insignificant for both blacks and whites.
} 
There were clear racial disparities in maternal and pneumonia/ influenza mortality throughout the period. The gap between blacks and whites in MMR was stable from 1925 to 1935 but widened after 1937 as a result of steeper declines in MMR among whites. Pneumonia/influenza appears to follow the same pattern, though the evidence of greater gaps after 1937 is not as clear (though these data are noisy). Somewhat surprisingly, mortality from scarlet fever was higher among whites than blacks in the pre-sulfa period, which the medical literature has attributed to lower susceptibility to scarlet fever among blacks (William M. Welch and Jay F. Schamberg 1905). Nevertheless after 1937, mortality from scarlet fever falls more rapidly for whites, and the black advantage is greatly diminished. Meanwhile, for the control disease, tuberculosis, there is no change in either black or white mortality around $1937 .{ }^{27}$

We next use regression analysis to estimate the magnitude of post-1937 changes in mortality for whites and blacks. Using the same difference-in-differences regression approach outlined in Section 5, we estimate equations 5.5 and 5.6 separately for blacks and whites and then pool the races and estimate models with race interactions, clustering the standard errors by disease-year. We use state-level data for this analysis rather than national-level data because by comparing blacks and whites in the same state, we can hold more factors constant (or closer to constant) such as the extent of urbanization or the health care system. ${ }^{28}$ The regressions include the 18 states in which blacks comprise at least $5 \%$ of the total population, which are mostly in the South. ${ }^{29}$ The black mortality rate has sizeable measurement error in states that have a small

\footnotetext{
${ }^{27}$ Interestingly, around 1945 when penicillin becomes available, the decline in tuberculosis mortality accelerates for whites but not blacks.

${ }^{28}$ The results using national data, which include whites and blacks from all states and use only one observation per year and disease and race, are qualitatively similar for both models, although the standard errors are larger. Results available upon request.

${ }^{29}$ These states are Alabama, Arkansas, Delaware, Florida, Georgia, Kentucky, Louisiana, Maryland, Mississippi, Missouri, New Jersey, North Carolina, Oklahoma, South Carolina, Tennessee, Texas, Virginia, and West Virginia.
} 
black population, and as we are running unweighted regressions, we exclude them to avoid reducing the precision of the estimates and introducing attenuation bias.

Table 6 reports the results. Sulfa drugs appear to have caused a 26\% decline in MMR for whites versus a $12 \%$ decline for blacks allowing for a level change after 1937 , or $42 \%$ versus $27 \%$ allowing for both a level and slope change. For pneumonia/influenza, our estimates suggest that sulfa drugs led to a $21 \%$ decline in mortality for whites and an $11 \%$ decline for blacks, or $35 \%$ versus $25 \%$ using the second model. For scarlet fever, we find that sulfa drugs had no statistically significant effect on scarlet fever mortality for blacks, but resulted in a 55-67\% decline in scarlet fever mortality for whites (the effect size is also much smaller for blacks; the coefficients imply a $13-21 \%$ decline).

To determine whether the differences in the coefficients for blacks and whites are statistically significant, we pool the race data and estimate fully interacted models. The results are shown in Panel C of Table 7 and confirm that whites experienced significantly greater mortality reductions from sulfa drugs than blacks for all of the treated diseases (positive interaction coefficients imply a smaller decline for blacks than whites). Appendix Table A2 shows that these results are robust to omitting 1935 to 1937 in our estimations.

Blacks were more likely to live in rural areas in this period, and our urban-rural results in the previous section suggest that location could be one explanation for why sulfa drugs seemed to diffuse more slowly among blacks. We do not have data at a disaggregated enough level to explore this hypothesis in the ideal manner, but we can regress state-level mortality on the percent black and percent rural in the state. We find that percent black is statistically significant conditional on percent rural, which suggests the smaller effect of sulfa drugs on black mortality 
is not just a rural effect and likely reflects segregation policies and the inferiority of the health care available to blacks. (Results available upon request.) ${ }^{30}$

Thus, whites appear to have benefited more from the introduction of sulfa drugs, in line with previous work that finds that medical innovation increases health gradients, at least initially. Sulfa drugs are a particularly interesting case because, unlike most life-saving innovations, they were inexpensive. The full course of medicine cost less than $\$ 100$ (2009 dollars). This suggests that factors other than income were the major barrier to accessing medical breakthroughs for low-SES groups like blacks.

\section{Conclusion}

This paper contributes to our understanding of the role that medical advances played in improving longevity in the first half of the $20^{\text {th }}$ century. Specifically, we examine the effect of sulfa drugs, whose discovery and rapid diffusion in the 1930s was one of the first major successes of modern pharmaceutical research. We use time series and difference-in-differences estimation methods, whereby we compare mortality patterns before and after sulfa drugs were introduced between treated and control diseases. Our results suggest that sulfa drugs caused significant mortality declines for the three causes of death included in our analysis: maternal mortality, pneumonia, and scarlet fever. Sulfa drugs led to a $25-40 \%$ decline in maternal mortality, a 17-36\% decline in pneumonia mortality, and a 52-67\% decline in scarlet fever mortality between 1937 and 1943. These findings imply that sulfa drugs reduced age-adjusted

\footnotetext{
${ }^{30}$ More generally, we investigated whether any state-level factors can explain differences in the adoption of sulfa drugs across states, where adoption was proxied by the level of mortality decline after 1937. Using our differencein-differences setup, we tested for an association between state characteristics-such as income per capita, high school graduation rates, number of doctors and hospitals per capita, percent of the population in urban areas and percent black — and mortality declines due to sulfa drugs. Our results were generally inconclusive (in most cases, not statistically significant and sensitive to specification choice). These results are available upon request.
} 
mortality by at least 2-4\% and increased life expectancy at birth by $0.4-0.8$ years. Thus, sulfa drugs had a significant impact on longevity, but most of the longevity gains during this era were due to other (probably non-medical) factors.

In addition, sulfa drugs seemed to benefit whites more than blacks, increasing racial inequality in maternal and pneumonia mortality and almost eliminating the black advantage in scarlet fever that existed before sulfa drugs became available. These results suggest that sulfa drugs diffused more rapidly among whites and support the hypothesis that medical innovation favors high-SES groups, at least initially. This finding is especially striking given that sulfa drugs were an inexpensive life-saving drug. Thus, one of the policy implications of our findings, which may be relevant for reducing infectious disease in developing countries today, is that while inventing and investing in new medical technology could be a promising way to combat disease, achieving equitable access to that technology may be a challenge, even for cheap and effective medical breakthroughs. 


\section{References}

Almond, Douglas, Kenneth Y. Chay, and Michael Greenstone. 2006. "Civil Rights, the War on Poverty, and Black-White Convergence in Infant Mortality in the Rural South and Mississippi.” MIT Department of Economics Working Paper 07-04.

Andrews, Donald W.K. 1993. "Tests for Parameter Instability and Structural Change with Unknown Change Point.” Econometrica 61(4): 821-856.

. 2003. “Tests for Parameter Instability and Structural Change with Unknown Change Point: A Corrigendum.” Econometrica 71(1): 395-397.

Bertrand, Marianne, Esther Duflo, and Sendhil Mullainathan. 2004. "How Much Should We Trust Differences-in-Differences Estimates?” Quarterly Journal of Economics 119(1): 249-275.

Colebrook, Leonard and Maeve Kenny. 1936a. “Treatment of Human Puerperal Infections, and of Experimental Infections in Mice with Prontosil.” Lancet 1:1279-1286.

.1936b. "Treatment with Prontosil of Puerperal Infections due to Haemolytic Streptococci.” Lancet 2:1319-1322.

Conybeare, John. 1948. “The Effects on Mortality of Recent Advances in Treatment.” Journal of Institute of Actuaries 74: 57-81.

Cutler, David M., Your Money or Your Life. Oxford, UK: Oxford University Press, 2004.

Cutler, David and Grant Miller. 2005. "The Role of Public Health Improvements in Health Advances: The Twentieth-Century United States.” Demography 42(1): 1-22.

Duke University, Medical Technology Assessment Working Group. 2006. Assessing the Impact of Medical Technology Innovations on Human Capital. Phase I Final Report (Part A): State-ofthe-Science Literature Reviews. Durham: Center for Demographic Studies, Duke University.

Evans, G.M., and Wilfrid.F. Gaisford. 1938. “Treatment of Pneumonia with 2-(p aminobenzenesulphonamide) pyridine.” Lancet 2: 14-18

Ferguson, N. M., A. P. Galvani, and R. M. Bush. 2003. "Ecological and Immunological Determinants of Influenza Evolution.” Nature 422: 428-43.

Fogel, Robert W. 1994. "Economic Growth, Population Theory, and Physiology: The Bearing of Long-Term Processes on the Making of Economic Policy." American Economic Review 84(3): 369-395.

Foulis M.A. and John B. Barr. 1937. "Prontosil Album in Puerperal Sepsis.” British Medical Journal 1:445-6. 
Gibberd G.F. 1937. "Prontosil and Similar Compound in the Treatment of Puerperal Haemolytic Streptococcus Infections.” British Medical Journal 2:695-698.

Glied, Sherry and Adriana Lleras-Muney. 2008. “Technological Innovation and Inequality in Health.” Demography 45(3): 741-761.

Goldman, Dana P. and Darius Noshir Lakdawalla. 2005. "A Theory of Health Disparities and Medical Technology.” Contributions to Economic Analysis \& Policy 4(1)8: 1-30.

Guyer, Bernard, Mary Anne Freedman, Donna M. Strobino, and Edward J. Sondik. 2000. "Annual Summary of Vital Statistics; Trends in the Health of Americans During the 20th Century.” Pediatrics 106:1307-1317.

Hamilton, Paul M. 1938. “Round Table Discussion of Sulfanilamide.” Journal of Pediatrics 13(4): 605-617.

Hecht. Annabel. 1984. "Sulfa; Yesterday's Hero is Still Taking Bows.” FDA Consumer 18 (Oct.).

Kiefer, David M. 2001. "Miracle Medicines. The Advent of the Sulfa Drugs in the Mid-1930s Gave Physicians a Powerful Weapon.” Today’s Chemist at Work 10(6): 59-60.

Lerner, Barron H. 1991. "Scientific Evidence Versus Therapeutic Demand: The Introduction of Sulfonamides Revisited.” Annals of Internal Medicine 115(4), 315-320.

Lesch, John E. 2007. The First Miracle Drugs: How the Sulfa Drugs Transformed Medicine. New York, NY: Oxford University Press.

Link, Bruce G., Mary E. Northridge, Jo C. Phelan and Michael L. Ganz. 1998. "Social Epidemiology and the Fundamental Cause Concept: On the Structuring of the Effective Cancer Screens by Socioeconomic Status. Milbank Quarterly 76 (3): 375-402.

Lofgren E., Fefferman N.H., Naumov Y.N., Gorski J., Naumova E.N. 2007. "Influenza Seasonality: Underlying Causes and Modeling Theories.” Journal of Virology. 81(11):5429-36.

Long, Perrin H. and Eleanor A. Bliss. 1937. "Observations upon the Experimental and Clinical Use of Sulphanilamode in the Treatment of Certain Infections.” Journal of the American Medical Association 108: 32-27. 1939. The Clinical and Experimental Use of Sulfanilamide, Sulfapyridine and Allied Compounds. New York: Macmillan.

Loudon, Irvine. 1987. "Puerperal Fever, the Streptococcus, and the Sulphonamides, 1911-1945.” British Medical Journal 22: 485-490. 
. 1988. "Maternal Mortality: 1800-1950. Some Regional and International Comparisons.” Social History of Medicine 1: 183-228. 73. . 1991. “On Maternal and Infant Mortality 1900-1960.” Social History of Medicine 4: 291992. Death in Childbirth. New York, NY: Oxford University Press. . 2002. "The Use of Historical Controls and Concurrent Controls to Assess the Effects of Sulphonamides, 1936-1945.” The James Lind Library (www.jameslindlibrary.org).

McKeown, Thomas. 1976. The Role of Medicine: Dream, Mirage, Nemesis. London: Nuffield Provincial Hospitals Trust.

McKinlay, John B. and Sonja M. McKinlay. 1977. "The Questionable Contribution of Medical Measures to the Decline of Mortality in the United States in the $20^{\text {th }}$ Century." The Milbank Memorial Fund Quarterly. Health and Society 55(3): 405-428.

McKeown, T., R.G. Record and R.D. Turner. 1975. “An Interpretation of the Decline of Mortality in England and Wales During the Twentieth Century.” Population Studies 29: 391421.

Nordhaus, William D. 2002. “The Health of Nations: The Contribution of Improved Health to Living Standards,” in Kevin Murphy and Robert Topel, eds., The Economic Value of Medical Research, University of Chicago Press, Chicago, 2002.

Perron, Pierre. 1989. "The Great Crash, the Oil Price Shock and the Unit Root Hypothesis,” Econometrica, 57, 1361-1401.

Preston, Samuel. 1996. “American Longevity: Past, Present, and Future” Maxwell School of Citizenship and Public Affairs, Center for Policy Research, Syracuse University, Working Paper No. 7/1996.

Preston, Samuel H. and Michael R. Haines. 1991. Fatal Years: Child Mortality in Late Nineteenth-Century America. Princeton, NJ: Princeton University Press.

Quandt, Richard E. 1960."Tests of the Hypothesis that a Linear Regression System Obeys Two Separate Regimes.” Journal of the American Statistical Association, 55 (290): 324-330

Pfuetze, Karl H. 1945. "Present Status of Chemotherapy in Tuberculosis from the Clinical Standpoint.” Chest. 11: 220-226.

Sappington, S.W. and G.O. Favorite. "Sulfanilamide and Meningitis.” Annals of Internal Medicine 13: S76-97. 
Schuman, Andrew J. 2003. “A Concise History of Antimicrobial Therapy (Serendipity and All).” Contemporary Pediatrics. 20(10): 66-85

Stock, James H. and Mark W. Watson. 2003. Introduction to Econometrics. Boston, MA: Pearson Education, Inc.

Thomasson, Melissa A., and Jaret Treber 2008. "From Home to Hospital: The Evolution of Childbirth in the United States, 1927-1940.” Explorations in Economic History 45(1): 76-99.

Weinshilboum, Richard M. 1987. "The Therapeutic Revolution.” Clinical Pharamcology \& Therapeutics 42(5): 481-4.

WHO, UNICEF and UNFPA. 2004. Maternal Mortality in 2000: Estimates Developed by WHO, UNICEF and UNFPA. Geneva: World Health Organization. 
Figure 1: Total mortality rate per 100,000 (in logs), 1920 - 1950

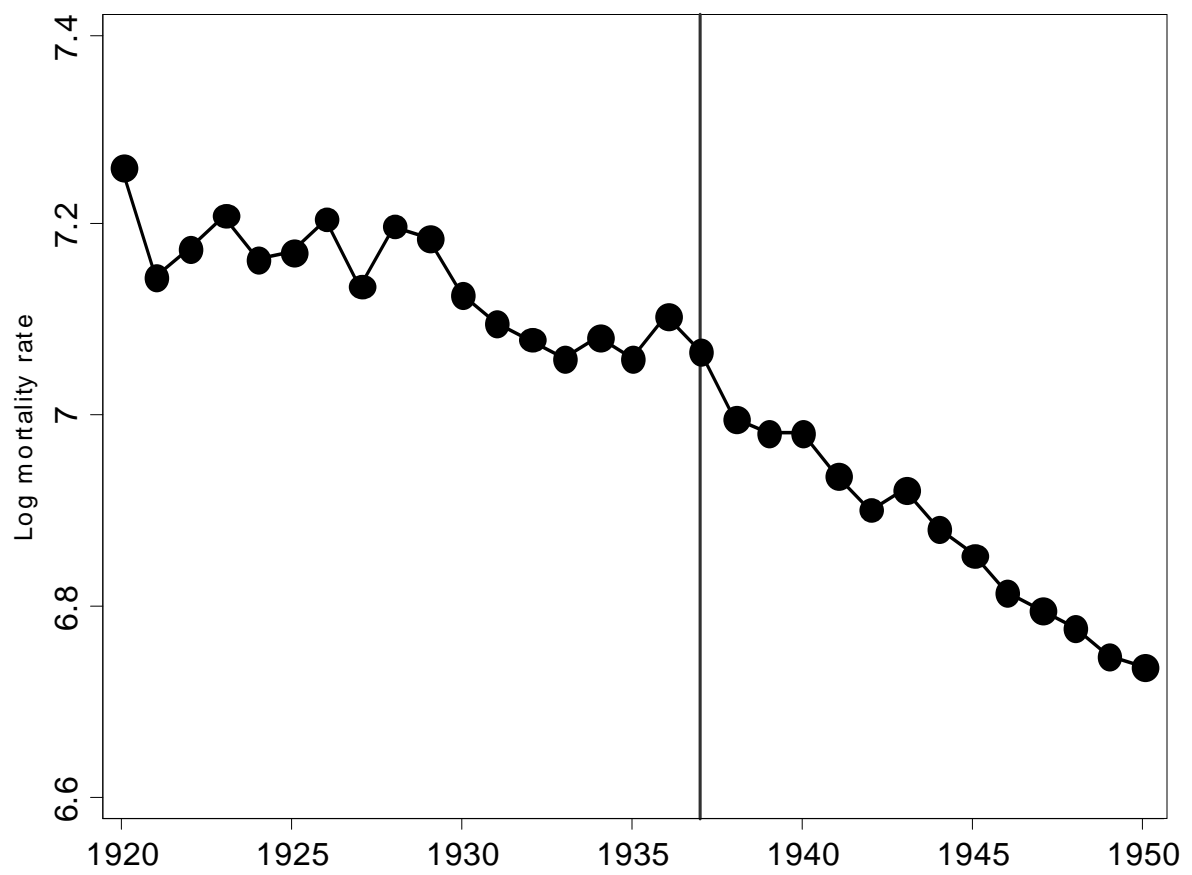


Figure 2: Mortality trends (in logs) for treated diseases, 1920 - 1950

a. Log maternal mortality ratio (deaths per 100,000 live births)

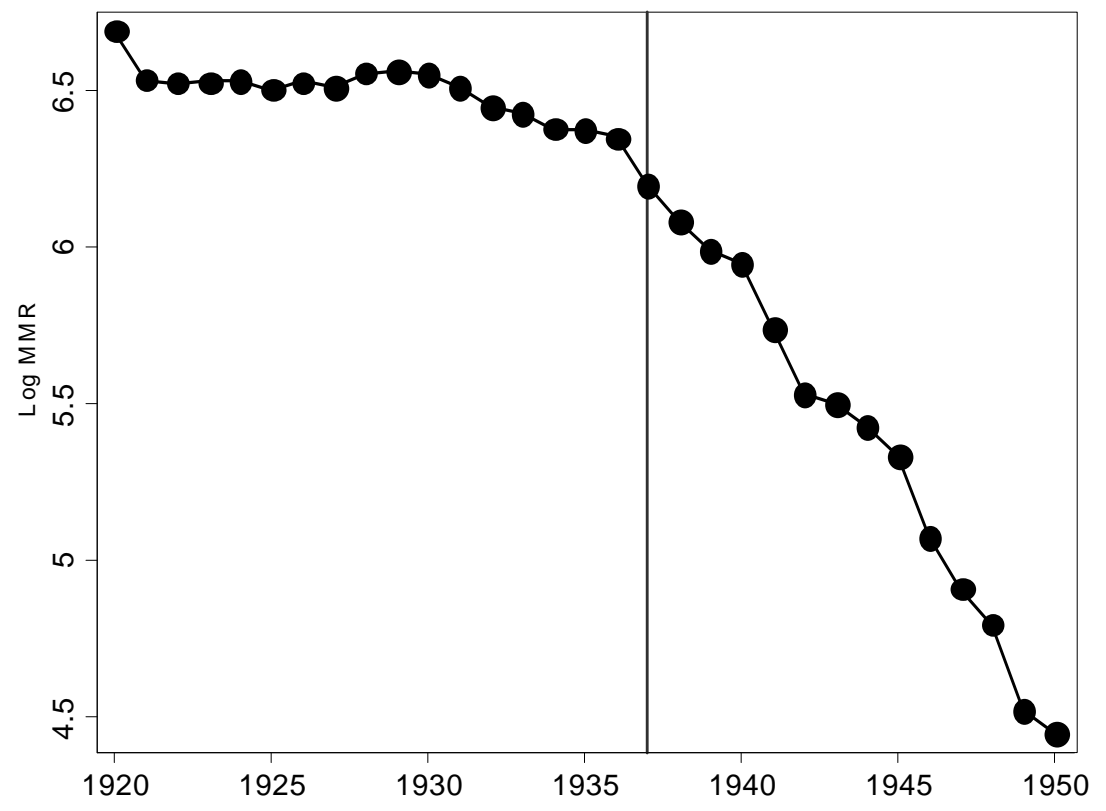

b. Log influenza and pneumonia mortality rate per 100,000

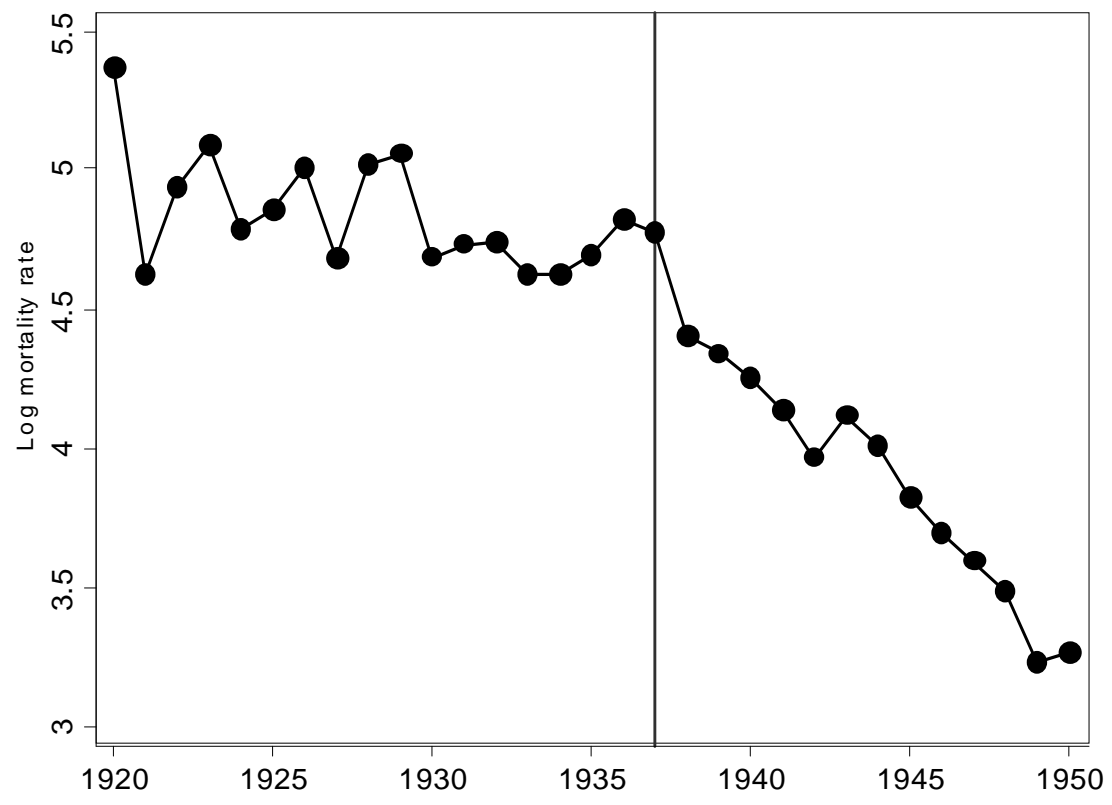


Figure 2, continued: Mortality trends (in logs) for treated diseases, 1920 - 1950

c. Log scarlet fever mortality rate per 100,000

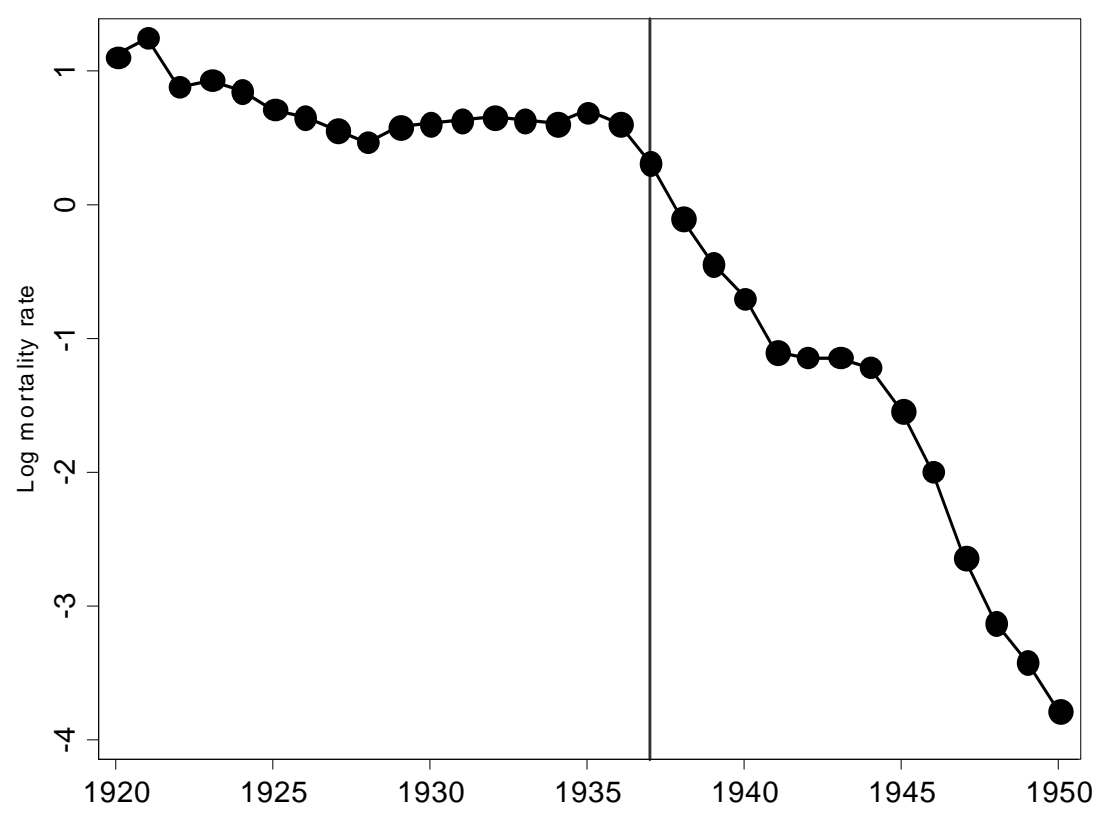

d. Log meningitis mortality rate per 100,000

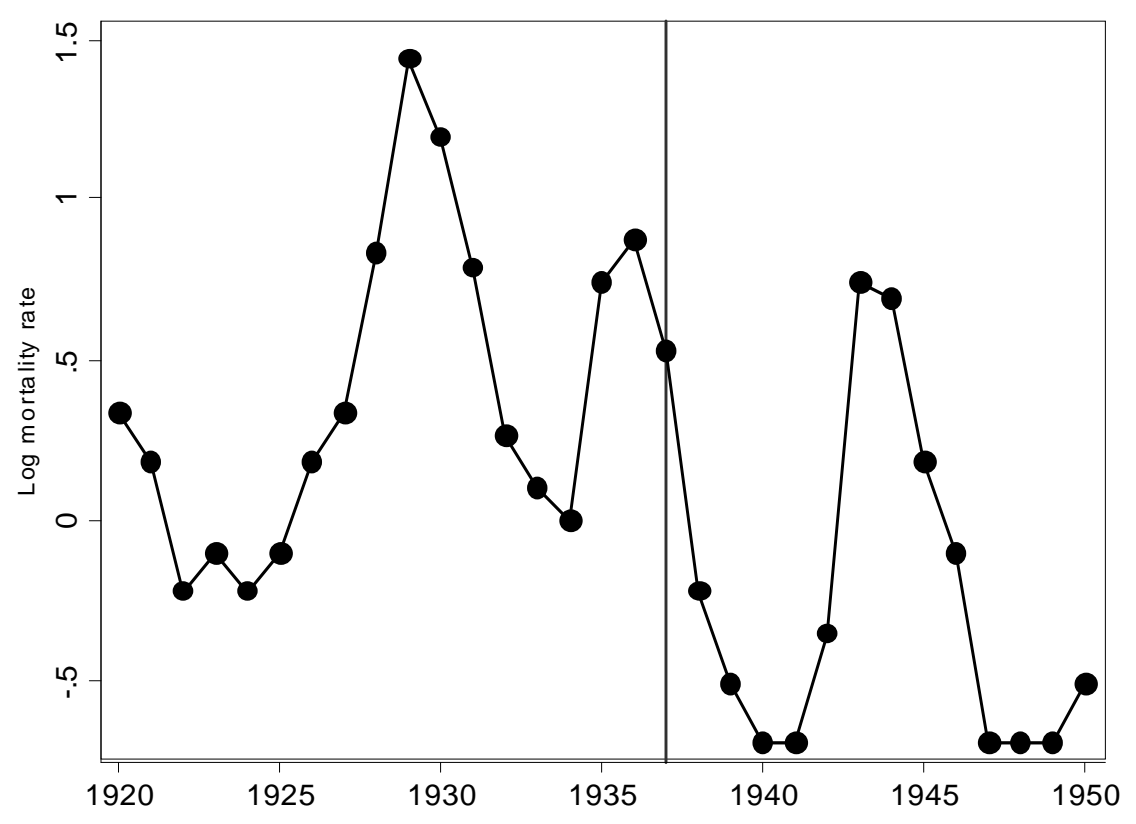


Figure 3: Mortality trends (in logs) for control disease

Log tuberculosis mortality rate per 100,000

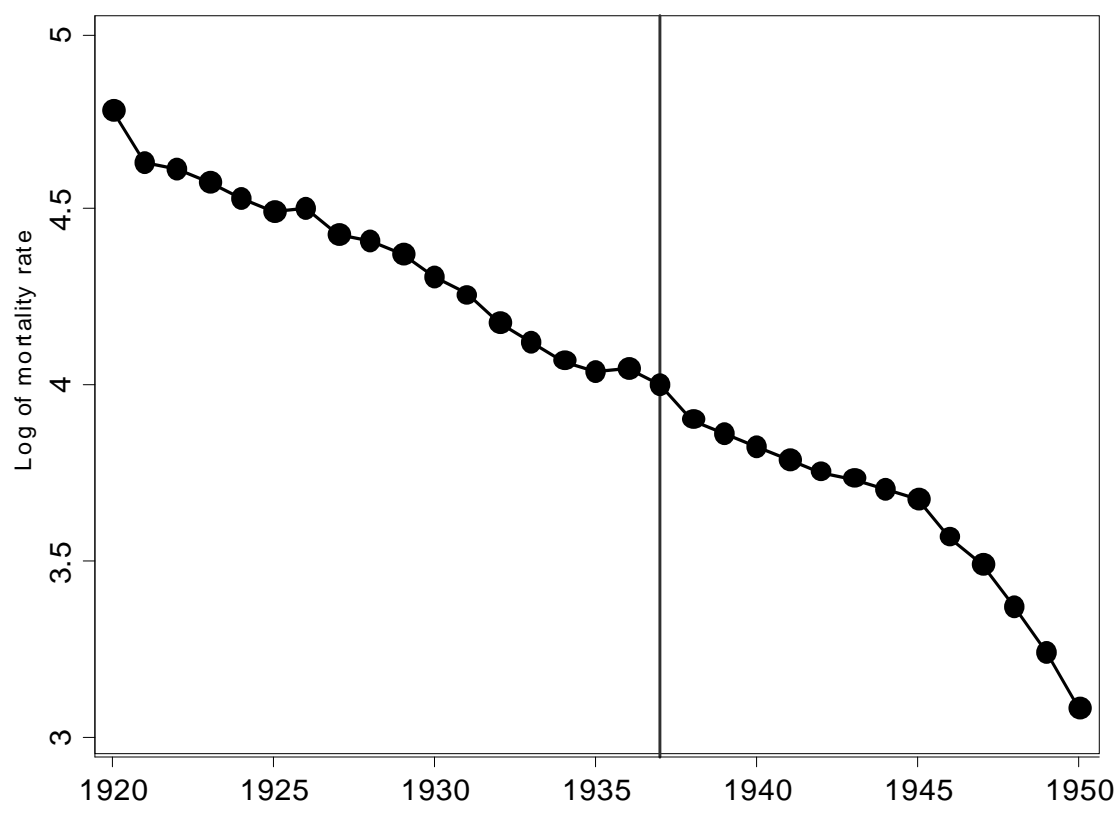

Figure 4: Mortality trends (in logs) for chronic diseases

Log mortality rate (per 100,000) for cancer, diabetes, and heart disease

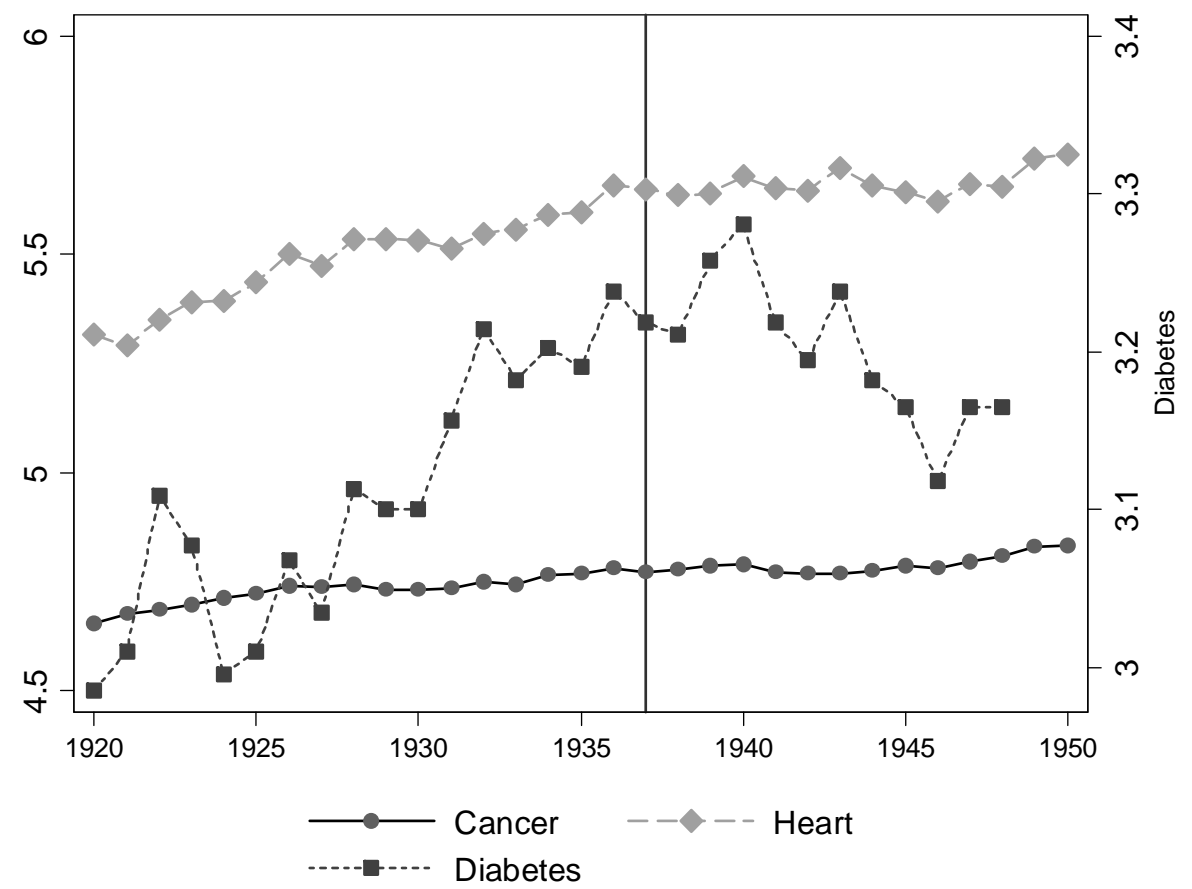


Figure 5: City and state trends in MMR (in logs), 1928 - 1940

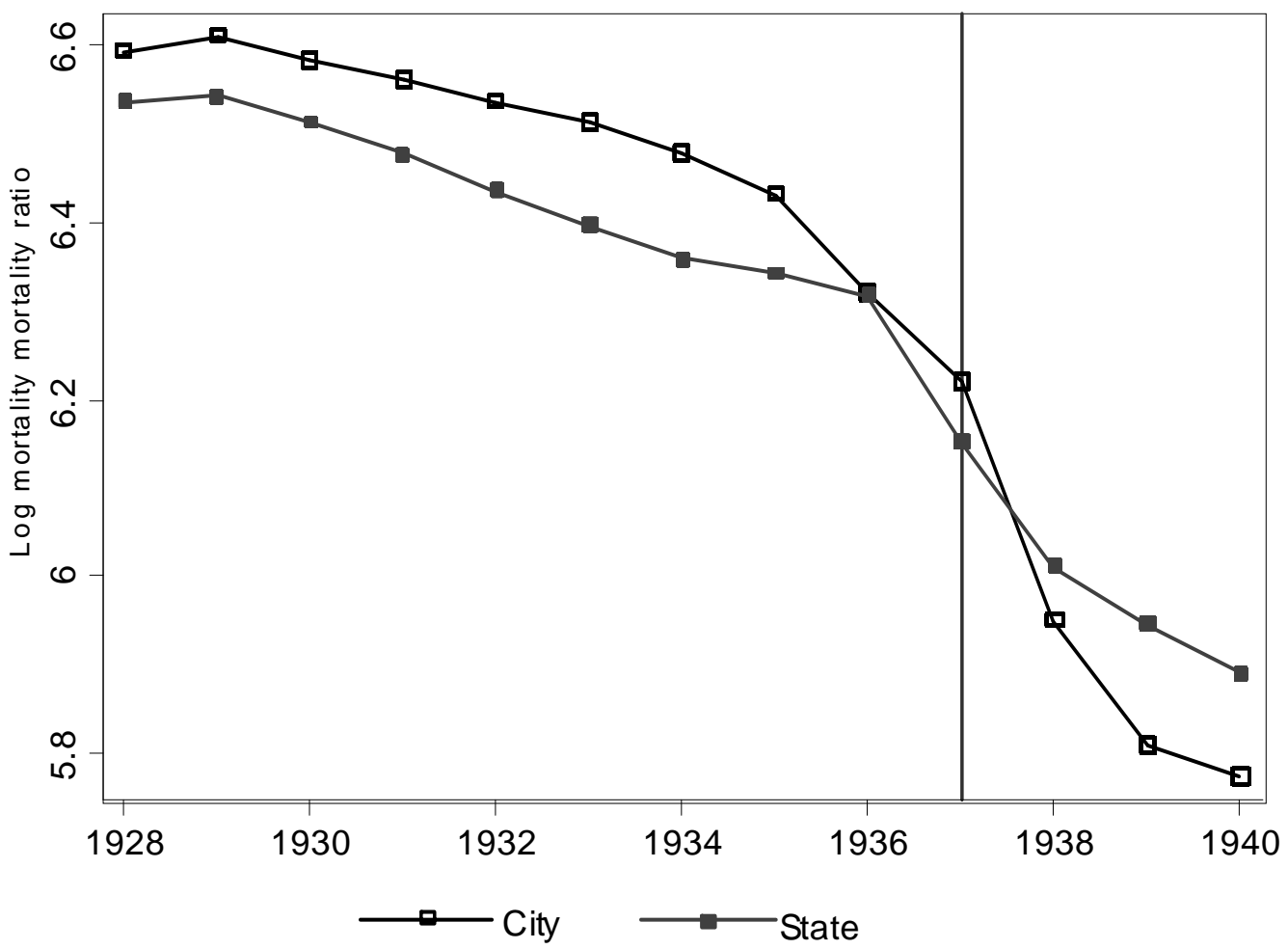

Note: The city series is the unweighted mean of the city-level observations and the state series is the unweighted mean of the state-level observations. 
Figure 6: Mortality trends (in logs) by race, 1920 - 1950

a: Log maternal mortality ratio, by race

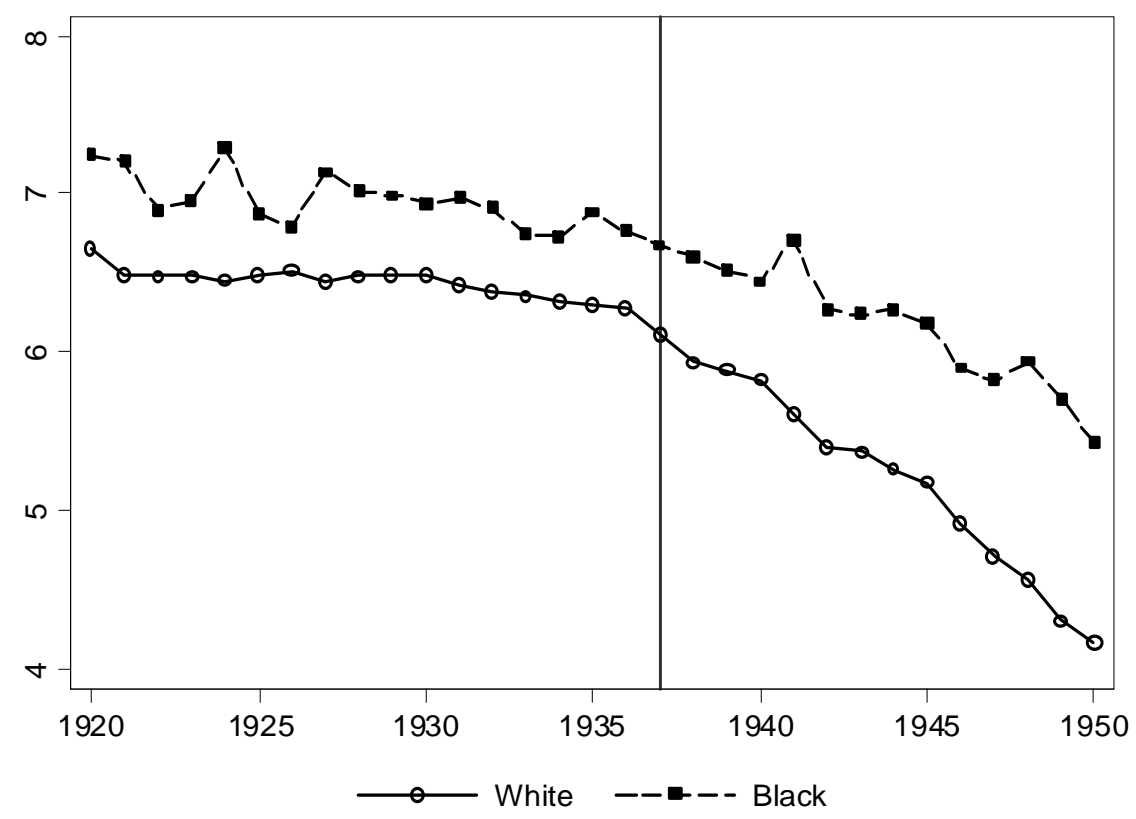

b: Log influenza and pneumonia mortality rate, by race

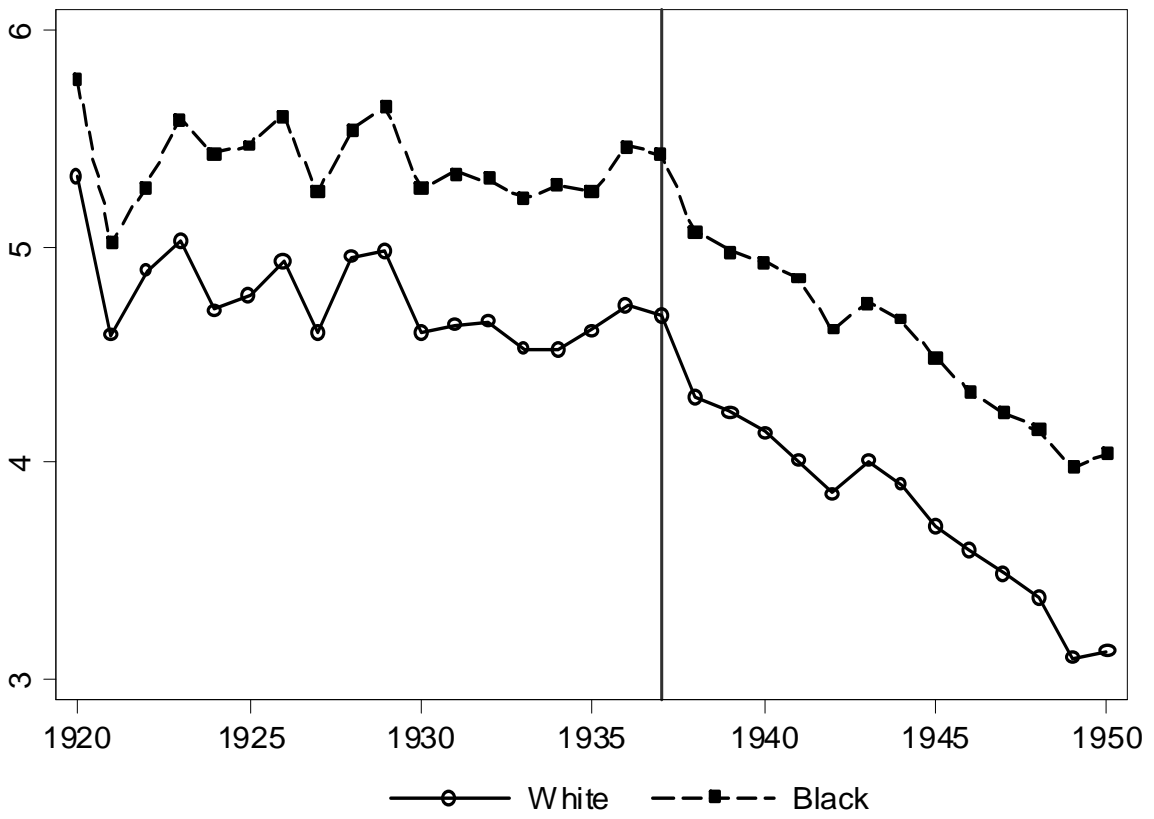


Figure 6, continued: Mortality trends (in logs) by race, 1920 - 1950

c: Log scarlet fever mortality rate, by race

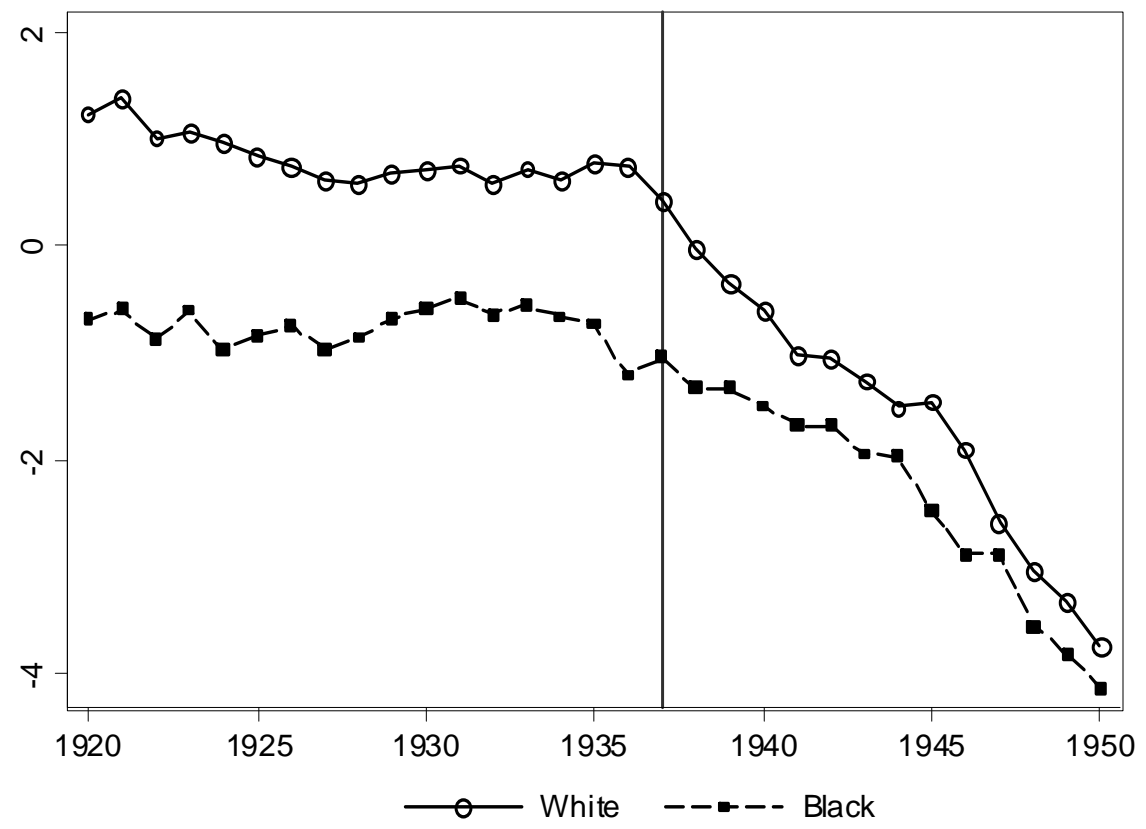

d: Log tuberculosis mortality rate, by race

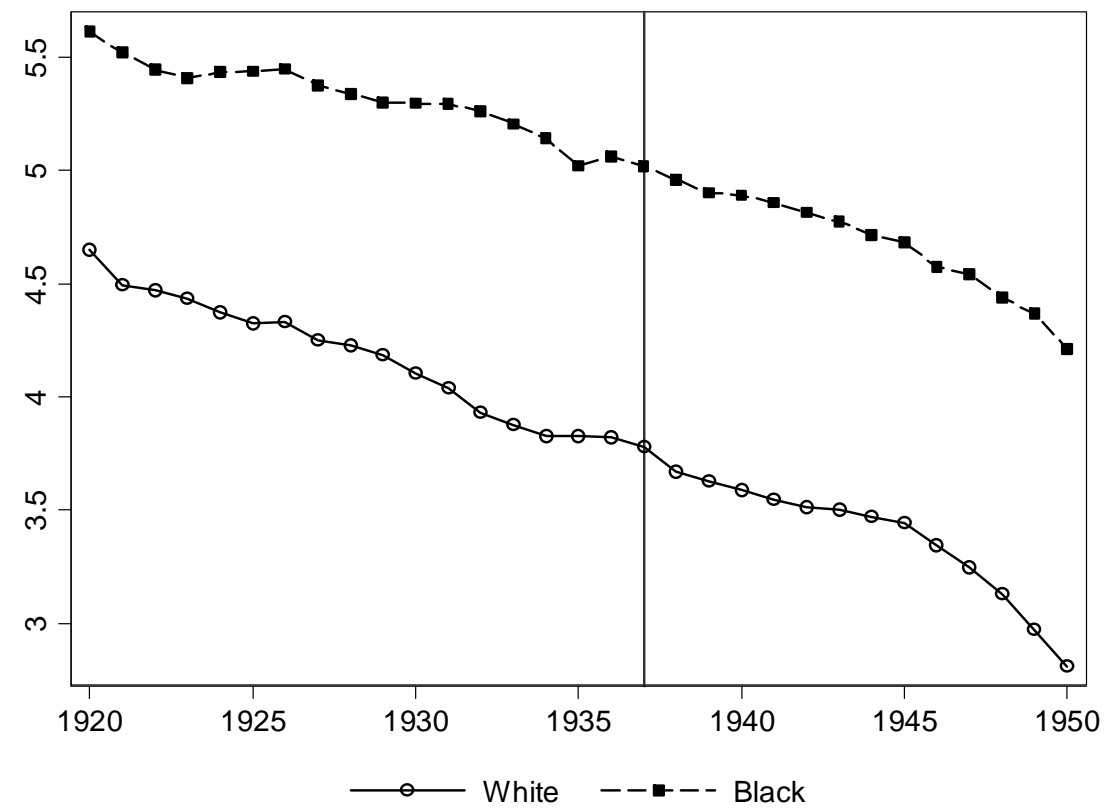


Table 1: National and state-level mortality statistics (deaths per 100,000)

\begin{tabular}{|c|c|c|c|c|c|c|c|c|c|c|}
\hline & \multicolumn{6}{|c|}{ Panel A: National mortality rates } & \multicolumn{4}{|c|}{ Panel B: Avg. state mortality rate } \\
\hline & \multirow{2}{*}{1920} & \multirow{2}{*}{1950} & \multicolumn{2}{|c|}{1925 to 1936} & \multicolumn{2}{|c|}{1937 to 1943} & \multicolumn{2}{|c|}{1925 to 1936} & \multicolumn{2}{|c|}{1937 to 1943} \\
\hline & & & Mean & S.D. & Mean & S.D. & Mean & S.D. & Mean & S.D. \\
\hline All-cause mortality & 1424 & 842 & 1245 & 66 & 1065 & 60 & & & & \\
\hline \multicolumn{11}{|l|}{ Treated diseases } \\
\hline MMR & 809 & 86 & 655 & 51 & 361 & 94 & 655 & 153 & 361 & 144 \\
\hline Pneumonia/influenza & 213 & 26 & 122 & 20 & 75 & 22 & 118 & 30 & 79 & 26 \\
\hline Scarlet Fever & 3.0 & 0.02 & 1.9 & 0.12 & 0.6 & 0.4 & 2.2 & 1.6 & 0.7 & 0.7 \\
\hline \multicolumn{11}{|l|}{ Control diseases } \\
\hline TB & 119 & 22 & 72 & 13 & 47 & 4 & 70 & 43 & 46 & 24 \\
\hline \multicolumn{11}{|l|}{ Chronic diseases } \\
\hline Diabetes & 20 & 14 & 23 & 2 & 25 & 1 & 19 & 7 & 23 & 8 \\
\hline Heart disease & 204 & 308 & 255 & 15 & 286 & 7 & 205 & 64 & 264 & 78 \\
\hline Cancer & 105 & 125 & 115 & 2 & 119 & 1 & 95 & 30 & 110 & 33 \\
\hline No. of states & & & & & & & $\begin{array}{c}39- \\
48\end{array}$ & & 48 & \\
\hline \multicolumn{11}{|l|}{ By race } \\
\hline MMR - White & 760 & 61 & 585 & 39 & 312 & 83 & 644 & 149 & 358 & 112 \\
\hline $\begin{array}{l}\text { MMR - Black } \\
\text { Pneumonia/influenza }\end{array}$ & 1281 & 222 & 1068 & 111 & 711 & 139 & 1139 & 322 & 739 & 214 \\
\hline $\begin{array}{l}\text { - White } \\
\text { Pneumonia/influenza }\end{array}$ & 204 & 23 & 112 & 19 & 67 & 20 & 123 & 19 & 75 & 22 \\
\hline - Black & 319 & 57 & 219 & 34 & 144 & 40 & 241 & 69 & 141 & 40 \\
\hline Scarlet Fever - White & 3.4 & 0.2 & 2.3 & 0.2 & 0.7 & 0.4 & 1.8 & 1.1 & 0.5 & 0.5 \\
\hline Scarlet Fever - Black & 0.5 & 0.0 & 0.6 & 0.1 & 0.3 & 0.08 & 0.7 & 0.8 & 0.3 & 0.4 \\
\hline TB - White & 105 & 17 & 59 & 12 & 37 & 4 & 72 & 19 & 38 & 12 \\
\hline TB - Black & 274 & 68 & 195 & 26 & 133 & 11 & 219 & 57 & 125 & 40 \\
\hline No. of states & na & na & na & na & na & na & $14-18$ & & 18 & \\
\hline
\end{tabular}

Notes: In Panel A, national mortality rates are age-adjusted (using the U.S. population in 1940 as the standard), except for MMR (maternal deaths per 100,000 births). The national and state summary statistics in Panels A and B are for years and states included in the regression analysis presented in Section 5 and 6 . The analysis in Section 5 includes all states; the race analysis in Section 6 includes 18 states with black populations greater than 5\% of the total state population. The state-level MMR data by race is only available for 10 of the 18 states in 1925; mortality rates for other causes by race are available for 14 of the 18 states in 1925. 
Table 2: Testing for year of trend break in national mortality series

\begin{tabular}{|c|c|c|}
\hline & Break year & Test statistic \\
\hline All-cause mortality & 1937 & 2.97 \\
\hline \multicolumn{3}{|c|}{ Diseases treated with sulfa drugs } \\
\hline MMR & $1937^{\star \star *}$ & 29.23 \\
\hline Pneumonia/influenza & 1938 & 3.09 \\
\hline Scarlet Fever & $1937^{\star \star \star}$ & 17.34 \\
\hline \multicolumn{3}{|l|}{ Control disease } \\
\hline TB & 1942 & 1.64 \\
\hline \multicolumn{3}{|c|}{$\begin{array}{l}\text { Notes: Dependent variable is the first difference of the log mortality rate. } \\
\text { Trend breaks are estimated using the Quandt Likelihood Ratio test for a } \\
\text { single trend break between } 1933 \text { and 1942, using age-adjusted mortality } \\
\text { data from } 1920 \text { to } 1950 \text { for all diseases except MMR. Newey-West } \\
\text { standard errors are used, allowing for autocorrelation in the error term for } \\
\text { up to two lags. The test statistic is the maximal F-statistic from a sequence } \\
\text { of Chow tests for each possible break date in the test window. Critical } \\
\text { values were obtained from Andrews (2003). }\end{array}$} \\
\hline
\end{tabular}


Table 3: Effect of sulfa drugs using national-level time series by disease, 1925-1943

\begin{tabular}{|c|c|c|c|c|c|c|c|c|c|c|}
\hline & \multicolumn{2}{|c|}{ All-cause } & \multicolumn{2}{|c|}{ MMR } & \multicolumn{2}{|c|}{ Pneumonia/influenza } & \multicolumn{2}{|c|}{ Scarlet fever } & \multicolumn{2}{|c|}{ TB } \\
\hline & (1) & $(2)$ & $(1)$ & $(2)$ & $(1)$ & $(2)$ & $(1)$ & $(2)$ & (1) & $(2)$ \\
\hline \multirow[t]{2}{*}{ Post-1937 } & -0.0244 & -0.00747 & $-0.304^{\star \star}$ & $-0.148^{\star \star \star}$ & -0.163 & -0.037 & $-0.862^{\star \star}$ & $-0.495^{\star \star \star}$ & 0.0151 & 0.0064 \\
\hline & $(0.023)$ & $(0.019)$ & $(0.140)$ & $(0.032)$ & $(0.120)$ & $(0.076)$ & $(0.360)$ & $(0.100)$ & $(0.025)$ & $(0.022)$ \\
\hline \multirow[t]{2}{*}{ Year*Post-1937 } & & $-0.012^{\star \star}$ & & $-0.108^{\star \star \star}$ & & $-0.087^{\star \star \star}$ & & $-0.254^{\star \star \star}$ & & 0.0061 \\
\hline & & $(0.005)$ & & $(0.009)$ & & $(0.026)$ & & $(0.033)$ & & $(0.006)$ \\
\hline Observations & 19 & 19 & 19 & 19 & 19 & 19 & 19 & 19 & 19 & 19 \\
\hline
\end{tabular}


Table 4: Effect of sulfa drugs on mortality for "treated" diseases, 1937 - 1943

\begin{tabular}{|c|c|c|c|c|c|c|}
\hline \multirow{2}{*}{ Dependent variable $=\ln$ (mortality) } & \multicolumn{2}{|c|}{ MMR } & \multicolumn{2}{|c|}{ Pneumonia/influenza } & \multicolumn{2}{|c|}{ Scarlet fever } \\
\hline & (1) & $(2)$ & (1) & (2) & (1) & (2) \\
\hline \multicolumn{7}{|c|}{ Panel A: National-level data, all years, 1925-1943 } \\
\hline \multirow[t]{2}{*}{ Treated*Post-1937 } & $-0.319 * \star$ & $-0.163^{\star \star \star}$ & -0.178 & -0.0521 & $-0.877^{\star *}$ & $-0.510^{\star \star *}$ \\
\hline & $(0.118)$ & $(0.041)$ & $(0.176)$ & $(0.126)$ & $(0.337)$ & $(0.110)$ \\
\hline \multirow[t]{2}{*}{ Treated*Year*Post-1937 } & & $-0.108^{\star \star \star}$ & & $-0.087^{\star \star \star}$ & & $-0.254^{\star \star \star}$ \\
\hline & & $(0.009)$ & & $(0.031)$ & & $(0.036)$ \\
\hline Observations & 38 & 38 & 38 & 38 & 38 & 38 \\
\hline R-squared & 0.99 & 1.00 & 0.91 & 0.95 & 0.99 & 1.00 \\
\hline
\end{tabular}

Panel B: State-level, all years, 1925-1943

\begin{tabular}{|c|c|c|c|c|c|c|}
\hline Treated*Post-1937 & $\begin{array}{l}-0.281^{\star \star} \\
(0.108)\end{array}$ & $\begin{array}{c}-0.144^{\star \star \star} \\
(0.035)\end{array}$ & $\begin{array}{l}-0.143 \\
(0.169)\end{array}$ & $\begin{array}{c}-0.0413 \\
(0.128)\end{array}$ & $\begin{array}{c}-0.733^{\star \star \star} \\
(0.267)\end{array}$ & $\begin{array}{c}-0.488^{\star \star \star} \\
(0.107)\end{array}$ \\
\hline Treated*Year*Post-1937 & & $\begin{array}{c}-0.103^{\star \star \star} \\
(0.010)\end{array}$ & & $\begin{array}{c}-0.0767^{\star \star} \\
(0.032)\end{array}$ & & $\begin{array}{c}-0.184^{\star \star \star} \\
(0.036)\end{array}$ \\
\hline Observations & 1736 & 1736 & 1736 & 1736 & 1720 & 1720 \\
\hline R-sq. & 0.999 & 0.999 & 0.822 & 0.839 & 0.932 & 0.940 \\
\hline
\end{tabular}

Panel C: State-level, excluding 1935 to 1937

Treated*Post-1937

Treated*Year*Post-1937

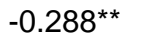

(0.134) $-0.125^{\star *}$

(0.054)

$-0.117^{\star \star *}$

(0.013)
$-0.0722-0.0258$

(0.093) (0.084)

$-0.0333$

(0.025) $-0.713^{\star \star *}-0.510^{\star \star *}$

$(0.255) \quad(0.129)$

$-0.146^{\star \star \star}$

(0.037)

Observations

1448

1448

0.999

0.999

$1448 \quad 1448$

$0.841 \quad 0.847$

1432

1432

Notes: "Treated" diseases refer to maternal mortality, pneumonia/influenza, and scarlet fever. Tuberculosis serves as the control disease. Post-1937 is equal to one for years from 1937 to 1943. National estimates (Panel A) are based on age-adjusted national mortality data from 1925 to 1943; robust standard errors are shown in parentheses. State estimates (Panels B and C) are based on 1925 to 1943 state-level mortality data; model (1) includes the main effect of Treated, state*post fixed effects, a continuous year variable, and its interaction with Treated and model (2) additionally includes state*post fixed effects and their interaction with the continuous year variable; robust standard errors, clustered by disease-year, are shown in parentheses. In the state analysis, 16 state/year observations are dropped from the scarlet fever model due to zero mortality from scarlet fever.

*** $p<0.01,{ }^{* *} p<0.05,{ }^{*} p<0.1$ 
Table 5: Urban-state differences in the effect of sulfa drugs on MMR

\begin{tabular}{lcc}
\hline \hline Dependent variable=In(MMR) & $(1)$ & $(2)$ \\
\hline Panel A: All years, 1928-1940 & & \\
Urban*Post-1937 & & $-0.093^{\star}$ \\
& $(0.042)$ & $(0.048)$ \\
Urban*Year*Post-1937 & & $-0.075^{\star \star *}$ \\
& & $(0.022)$ \\
Observations & & 3966 \\
R-squared & 3966 & 0.942 \\
\hline & 0.939 & \\
Panel B: Excluding 1935 to 1937 & & $-0.298^{\star \star *}$ \\
Urban*Post-1937 & & $(0.083)$ \\
& $-0.329 * \star *$ & -0.024 \\
Observations & $(0.063)$ & $(0.033)$ \\
\hline Urban*Year*Post-1937 & & 3038 \\
& & 0.943 \\
\hline
\end{tabular}

Notes: Estimates are based on 1928 to 1940 mortality data for cities with populations of at least 25,000 (as of 1930) and for states. Post-1937 equals one for years from 1937 to 1940 . Model (1) includes the main effect of Urban, state*post fixed effects, and a continuous year variable and its interaction with Urban. Model (2) additionally includes state*post fixed effects and their interaction with the continuous year variable.

Robust standard errors, clustered by disease-year, are shown in parentheses.

${ }^{\star} p<.10 ;{ }^{* *} p<.05 ;{ }^{* *} p<.01$ 
Table 6: Racial differences in the effect of sulfa drugs on mortality, 1937-1943

\begin{tabular}{|c|c|c|c|c|c|c|}
\hline & \multicolumn{2}{|c|}{ MMR } & \multicolumn{2}{|c|}{ Pneumonia/influenza } & \multicolumn{2}{|c|}{ Scarlet fever } \\
\hline & $(1)$ & $(2)$ & (1) & $(2)$ & (1) & $(2)$ \\
\hline \multicolumn{7}{|l|}{ Panel A: Whites } \\
\hline \multirow[t]{2}{*}{ Treated*Post-1937 } & $-0.301^{* *}$ & 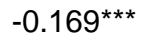 & -0.230 & -0.104 & $-0.804^{\star \star \star}$ & $-0.582^{\star \star \star}$ \\
\hline & $(0.115)$ & $(0.044)$ & $(0.183)$ & $(0.122)$ & $(0.221)$ & $(0.164)$ \\
\hline \multirow[t]{2}{*}{ Treated*Year*Post-1937 } & & $-0.109 \star \star \star$ & & $-0.094^{\star \star \star}$ & & $-0.155^{\star \star \star}$ \\
\hline & & $(0.010)$ & & $(0.027)$ & & $(0.032)$ \\
\hline Obs. & 644 & 644 & 652 & 652 & 539 & 539 \\
\hline R-sq. & 0.998 & 0.998 & 0.856 & 0.883 & 0.976 & 0.981 \\
\hline \multicolumn{7}{|l|}{ Panel B: Blacks } \\
\hline \multirow[t]{2}{*}{ TreatedPost-1937 } & -0.133 & -0.029 & -0.115 & -0.013 & -0.134 & -0.124 \\
\hline & $(0.096)$ & $(0.061)$ & $(0.165)$ & $(0.132)$ & $(0.187)$ & $(0.155)$ \\
\hline \multirow[t]{2}{*}{ Treated*Year*Post-1937 } & & $-0.081^{\star \star \star}$ & & $-0.076^{\star \star \star}$ & & -0.032 \\
\hline & & $(0.013)$ & & $(0.027)$ & & $(0.032)$ \\
\hline Obs. & 644 & 644 & 652 & 652 & 500 & 500 \\
\hline R-sq. & 0.997 & 0.997 & 0.788 & 0.826 & 0.983 & 0.984 \\
\hline \multicolumn{7}{|l|}{ Panel C: Fully interacted model } \\
\hline \multirow[t]{2}{*}{ Treated*Post-1937*Black } & $0.168^{\star \star}$ & $0.140 * \star$ & $0.115^{\star \star}$ & $0.091^{\star *}$ & $0.671^{\star \star \star}$ & $0.458^{\star \star \star}$ \\
\hline & $(0.068)$ & $(0.052)$ & $(0.052)$ & $(0.043)$ & $(0.211)$ & $(0.157)$ \\
\hline \multirow[t]{2}{*}{ Treated*Year*Post-1937*Black } & & $0.028^{\star \star \star}$ & & $0.018^{\star \star}$ & & $0.123^{\star \star}$ \\
\hline & & $(0.010)$ & & $(0.009)$ & & $(0.048)$ \\
\hline Obs. & 1288 & 1288 & 1304 & 1304 & 1039 & 1039 \\
\hline R-sq. & 0.997 & 0.998 & 0.918 & 0.933 & 0.981 & 0.983 \\
\hline \multicolumn{7}{|c|}{$\begin{array}{l}\text { Notes: Treated diseases refer to maternal mortality, pneumonia/flu, and scarlet fever. Tuberculosis serves as } \\
\text { the control disease. Estimates are based on } 1925 \text { to } 1943 \text { state-level mortality data. Only states with black } \\
\text { populations greater than or equal to } 5 \% \text { of the total population in } 1936 \text { are included (18 states for MMR and } \\
\text { pneumonia/influenza models). In three states, MMR data by race are available four years later than } \\
\text { pneumonia/influenza and scarlet fever data by race, which results in a total of } 8 \text { fewer state/year/race } \\
\text { observations in the MMR models for each race. In the scarlet fever models, six states are dropped from the } \\
\text { analysis due to a large proportion of year/state observations with zero mortality for blacks. In Panels A and B, } \\
\text { Model (1) includes the main effect of Treated, state*post fixed effects, a continuous year variable, and its } \\
\text { interaction with Treated; Model (2) additionally includes state*post fixed effects and their interaction with the } \\
\text { continuous year variable. In Panel C, Models (1) and (2) include each of the same variables as in the previous } \\
\text { panels plus their interaction with Black. Robust standard errors, clustered by disease-year, are in parentheses. } \\
{ }^{*} p<.10,{ }^{* *} p<.05,{ }^{* \star *} p<.01\end{array}$} \\
\hline
\end{tabular}


Table A1: Robustness check: difference-in-difference regressions, dropping 1935-1936

\begin{tabular}{|c|c|c|c|c|}
\hline \multirow{2}{*}{ Dependent variable $=\ln$ (mortality) } & \multicolumn{2}{|c|}{ MMR } & \multicolumn{2}{|c|}{ Scarlet fever } \\
\hline & (1) & (2) & (1) & $(2)$ \\
\hline \multicolumn{5}{|c|}{ Panel A: Effect of sulfa drugs on mortality (Table 4) } \\
\hline Treated*Post-1937 & $\begin{array}{c}-0.183 \\
(0.147)\end{array}$ & $\begin{array}{c}-0.170 \text { *** } \\
(0.042)\end{array}$ & $\begin{array}{l}-0.416 \\
(0.330)\end{array}$ & $\begin{array}{c}-0.391^{\star * \star} \\
(0.114)\end{array}$ \\
\hline Treated*Year*Post-1937 & & $\begin{array}{c}-0.106^{\star \star \star} \\
(0.010)\end{array}$ & & $\begin{array}{c}-0.173^{\star \star *} \\
(0.036)\end{array}$ \\
\hline Obs. & 1544 & 1544 & 1528 & 1528 \\
\hline R-sq. & 0.999 & 0.999 & 0.941 & 0.948 \\
\hline
\end{tabular}

Panel B: Urban-state differences in the effect of sulfa drugs on the MMR (Table 5)

Urban*Post-1937

$$
\begin{array}{cc}
-0.201^{\star * \star} & -0.157^{\star \star *} \\
(0.055) & (0.049)
\end{array}
$$

Urban*Year*Post-1937

$-0.084^{\star \star *}$

Observations

3348

3348

R-squared

0.94

0.94

Notes: Panel A estimates are based on 1925 to 1943 state-level mortality data. Model (1) includes the main effect of Treated, state*post fixed effects, a continuous year variable, and its interaction with Treated; Model (2) additionally includes state*post fixed effects and their interaction with the continuous year variable. Panel B estimates are based on 1928 to 1940 city-level data and state data. Model (1) includes the main effect of Urban, state*post fixed effects, a continuous year variable, and its interaction with Urban; Model (2) additionally includes state*post fixed effects and their interaction with the continuous year variable. For all regressions, robust standard errors, clustered by disease-year, are shown in parentheses.

${ }^{*} \mathrm{p}<.10,{ }^{* *} \mathrm{p}<.05,{ }^{* * *} \mathrm{p}<.01$ 
Table A2: Robustness check: Racial differences, dropping 1935-1937

\begin{tabular}{|c|c|c|c|c|c|c|}
\hline & \multicolumn{2}{|c|}{ MMR } & \multicolumn{2}{|c|}{ Pneumonia/influenza } & \multicolumn{2}{|c|}{ Scarlet fever } \\
\hline & (1) & $(2)$ & $(1)$ & $(2)$ & (1) & $(2)$ \\
\hline \multicolumn{7}{|l|}{ Panel A: Whites } \\
\hline Treated*Post-1937 & $\begin{array}{c}-0.329 \star \star \\
(0.142)\end{array}$ & $\begin{array}{c}-0.176^{\star \star} \\
(0.069)\end{array}$ & $\begin{array}{l}-0.214 \\
(0.130)\end{array}$ & $\begin{array}{l}-0.127 \\
(0.108)\end{array}$ & $\begin{array}{c}-1.281^{\star \star \star} \\
(0.307)\end{array}$ & $\begin{array}{c}-0.971 * \star \star \\
(0.155)\end{array}$ \\
\hline Treated*Year*Post-1937 & & $\begin{array}{c}-0.125^{\star \star \star} \\
(0.015)\end{array}$ & & $\begin{array}{c}-0.0615^{\star *} \\
(0.024)\end{array}$ & & $\begin{array}{c}-0.211^{\star * *} \\
(0.037)\end{array}$ \\
\hline Obs. & 536 & 536 & 544 & 544 & 449 & 449 \\
\hline R-sq. & 0.998 & 0.998 & 0.876 & 0.885 & 0.978 & 0.983 \\
\hline \multicolumn{7}{|l|}{ Panel B: Blacks } \\
\hline Treated*Post-1937 & $\begin{array}{l}-0.098 \\
(0.136)\end{array}$ & $\begin{array}{c}0.025 \\
(0.079)\end{array}$ & $\begin{array}{l}-0.053 \\
(0.106)\end{array}$ & $\begin{array}{l}-0.011 \\
(0.093)\end{array}$ & $\begin{array}{c}-0.470 * \star \\
(0.201)\end{array}$ & $\begin{array}{l}-0.377 \\
(0.226)\end{array}$ \\
\hline Treated*Year*Post-1937 & & $\begin{array}{c}-0.092^{\star * \star} \\
(0.015)\end{array}$ & & $\begin{array}{l}-0.030 \\
(0.020)\end{array}$ & & $\begin{array}{l}-0.060 \\
(0.045)\end{array}$ \\
\hline $\begin{array}{l}\text { Obs. } \\
\text { R-sq. }\end{array}$ & $\begin{array}{c}536 \\
0.997\end{array}$ & $\begin{array}{c}536 \\
0.997\end{array}$ & $\begin{array}{c}544 \\
0.846\end{array}$ & $\begin{array}{c}544 \\
0.859\end{array}$ & $\begin{array}{c}417 \\
0.983\end{array}$ & $\begin{array}{c}417 \\
0.985\end{array}$ \\
\hline Panel C: Fully interacted mod & & & & & & \\
\hline Treated*Post-1937Black & $\begin{array}{l}0.231^{\star *} \\
(0.096)\end{array}$ & $\begin{array}{l}0.201^{\star \star} \\
(0.081)\end{array}$ & $\begin{array}{l}0.161^{\star \star} \\
(0.072)\end{array}$ & $\begin{array}{c}0.116 \\
(0.069)\end{array}$ & $\begin{array}{l}0.812^{\star \star} \\
(0.342)\end{array}$ & $\begin{array}{l}0.594^{\star \star} \\
(0.289)\end{array}$ \\
\hline Treated*Year*Post-1937*Black & & $\begin{array}{c}0.0327^{\star *} \\
(0.015)\end{array}$ & & $\begin{array}{c}0.0318^{\star \star} \\
(0.012)\end{array}$ & & $\begin{array}{l}0.151^{\star \star} \\
(0.069)\end{array}$ \\
\hline Obs. & 1072 & 1072 & 1088 & 1088 & 866 & 866 \\
\hline R-sq. & 0.997 & 0.998 & 0.935 & 0.940 & 0.982 & 0.985 \\
\hline
\end{tabular}

Notes: Treated diseases refer to maternal mortality, pneumonia/flu, and scarlet fever. Tuberculosis serves as the control disease. Estimates are based on 1925 to 1943 state-level mortality data. Only states with black populations greater than or equal to $5 \%$ of the total population in 1936 are included (18 states for MMR and pneumonia/influenza models). In three states, MMR data by race are available four years later than pneumonia/influenza and scarlet fever data by race, which results in a total of 8 fewer state/year/race observations in the MMR models for each race. In the scarlet fever models, six states are dropped from the analysis due to a large proportion of year/state observations with zero mortality for blacks. In Panels A and B, Model (1) includes the main effect of Treated, state*post fixed effects, a continuous year variable, and its interaction with Treated; Model (2) additionally includes state*post fixed effects and their interaction with the continuous year variable. In Panel C, Models (1) and (2) include the same variables as in the previous panels plus their interaction with Black. Robust standard errors, clustered by disease-year, are in parentheses.

${ }^{*} p<.10,{ }^{* *} p<.05, * * * p<.01$ 